\title{
Effect of Calcium on Dissolution and Precipitation Reactions of Amorphous Silica at High Alkalinity
}

4

\author{
Hamed Maraghechi ${ }^{1}$, Farshad Rajabipour ${ }^{2}$, Carlo G. Pantano ${ }^{3}$, William D. Burgos ${ }^{4}$
}

1. (corresponding author) Post-doctoral Scientist, Laboratory of Construction Materials, Institute of Materials, Ecole Polytechnique Fédérale de Lausanne (EPFL), Switzerland, hamed.maraghechi@epfl.ch

2. Associate Professor, Department of Civil and Environmental Engineering, Pennsylvania State University, University Park, Pennsylvania 16802, USA, farshad@psu.edu, (ph)+1-814-863-0601

3. Distinguished Professor, Department of Materials Science and Engineering, Pennsylvania State University, University Park, Pennsylvania 16802, USA, cgp1@psu.edu

4. Professor, Department of Civil and Environmental Engineering, Pennsylvania State University, University Park, Pennsylvania 16802, USA, wdb3@psu.edu

\section{Abstract}

A better understanding of silica dissolution-precipitation reactions at high $\mathrm{pH}$ aqueous solutions allows for promotion of favorable (e.g., pozzolanic) reactions and mitigation of deleterious (e.g., alkali-silica) reactions in concrete. In this paper, the kinetics and products of silica glass dissolution are studied as a function of solution $\mathrm{pH}$, temperature, and availability of calcium. It was observed that dissolution rate versus time increases linearly with $\mathrm{pH}$ and reaches a maximum at $\mathrm{pH}=14$, with slower dissolution at higher alkalinities. In solutions with similarly high $\mathrm{pH}$, but saturated with portlandite, glass dissolution is significantly slower. This is due to formation of a dense, low porosity, and strongly bonded C-S-H layer on the surface of glass, which serves as a barrier against diffusion of $\mathrm{OH}^{-}$and alkali ions towards the substrate glass. This protective layer forms only when $\mathrm{Ca}$ is abundant and portlandite saturation can be maintained on a local scale. 
34 Keywords: Kinetics (A), pH (A), Glass (B), Alkali-Aggregate Reaction (C), Pozzolan (D)

\section{Introduction}

37 Several important chemical reactions in concrete, such as the pozzolanic, geopolymeric, and alkali-silica reactions (ASR) begin with dissolution of amorphous or otherwise metastable metal-silicate phases (e.g., from fly ash, slag, or reactive aggregates) into the alkaline pore solution of concrete. The dissolved species subsequently react and precipitate as a binding material, such as calcium silicate hydrate (C-S-H or C-(A)-S-H), or a swelling gel (e.g., ASR gel). Therefore, study of the dissolution and precipitation characteristics of metal-silicates in alkaline solutions helps in better understanding and controlling these reactions. For this purpose, commercial soda-lime and fused silica glasses were used as simple models in this study. A further goal of this research was to investigate the reactivity of soda-lime glass (a potential pozzolan or aggregate source obtained by recycling glass bottles and window plates [1]) in environments similar to concrete pore solution. The findings can also benefit the durability, in exposure to alkaline environments, of multi-oxide glasses encapsulating radioactive waste [2].

Specifically, the following objectives were pursued in this study:

1. To quantify the kinetics of silicate glass dissolution at high alkalinity $(12.0<\mathrm{pH}<14.9)$, similar to those that exist in the pore solutions of portland cement and alkali-activated concretes.

2. To investigate the nature and characteristics of solid products, resulting from dissolution of soda-lime glass. 


$$
\equiv \mathrm{Si}-\mathrm{O}-\mathrm{Na}_{(\mathrm{s})}+\mathrm{H}_{(\mathrm{aq})}^{+} \stackrel{\text { leaching }}{\longrightarrow} \equiv \mathrm{Si}-\mathrm{OH}_{(\mathrm{s})}+\mathrm{Na}_{(\mathrm{aq})}^{+}
$$
the papers by Scholze $[15,16]$ and Bunker [8], which reviewed the mechanisms of water- 
81 glass interactions during leaching of cations. As alkalis diffuse out of the glass surface, a Sirich altered layer, known as the gel-layer, forms which could condense and act as a barrier against further diffusion of ions into and out of glass [17]. As discussed below, the altered gel layer on the surface of glass can also form in exposure to alkaline solutions, and this has been documented within the domain of nuclear glass research [18].

\subsection{Network (congruent) dissolution}

Network dissolution (or hydrolysis) occurs at high $\mathrm{pH}$, where the polar siloxane (Si-O) bonds are broken through a nucleophilic attack of hydroxyl ions (OH-), according to Eq. 2 [17,18]. In fact, the surface of silicate glass that is exposed to water is almost always hydrolyzed, and $\equiv$ Si-OH groups are abundant $[19,20]$. The reverse reaction in Eq. 2 is called "condensation", as it results in liberation of water.

$$
\equiv \mathrm{Si}-\mathrm{O}-\mathrm{Si} \equiv+\mathrm{OH}^{-} \mathrm{H}^{+} \stackrel{\text { hydrolysis }}{\longrightarrow} \equiv \mathrm{Si}-\mathrm{OH}+\mathrm{HO}-\mathrm{Si} \equiv
$$

The forward reaction presented in Eq. 2 can proceed further to dissolve a silica monomer into solution according to Eq. 3.

97

$$
\mathrm{SiO}_{2(\mathrm{~s})}+2 \mathrm{H}_{2} \mathrm{O} \stackrel{\text { dissolution }}{\longrightarrow} \mathrm{Si}(\mathrm{OH})_{4(\mathrm{aq})} \quad \operatorname{LogK}_{\mathrm{sp}}=-2.92
$$

98

At neutral $\mathrm{pH}$, the solubility limit of silica is low and is reported to be 1.93 and $0.10 \mathrm{mM}$ at $25^{\circ} \mathrm{C}$ for vitreous silica and crystalline quartz, respectively [21,22]. At high $\mathrm{pH}, \mathrm{Si}(\mathrm{OH})_{4}$ monomers undergo ionization (Eqs. 4 and 5) to form highly soluble $\mathrm{SiO}(\mathrm{OH})_{3}{ }^{-}$and $\mathrm{SiO}_{2}(\mathrm{OH})_{2}{ }^{2-}$ ions (alternatively written as $\mathrm{H}_{3} \mathrm{SiO}_{4}{ }^{-}$and $\mathrm{H}_{2} \mathrm{SiO}_{4}{ }^{2-}$ ) [17]. The solubility of these ions becomes significant at $\mathrm{pH}$ values higher than 10 [23]. 


$$
\mathrm{Si}(\mathrm{OH})_{4} \leftrightarrow \mathrm{SiO}(\mathrm{OH})_{3}^{-}+\mathrm{H}^{+} \quad \log _{1}=-9.47
$$

105

$$
\mathrm{Si}(\mathrm{OH})_{4} \leftrightarrow \mathrm{SiO}_{2}(\mathrm{OH})_{2}^{2-}+2 \mathrm{H}^{+} \quad \operatorname{LogK}_{2}=-22.12 \quad \text { (Eq. 5) }
$$

106

107 In addition to the mono-silicic species, larger dissolved silicates such as di-, tri, and tetra-

108 mers, as well as linear or cyclic oligomers may be present at lower concentrations in the

109 solution (their thermodynamic data are given in $[23,24,25]$ ). Based on Eqs. 3-5, the solubility

110 limit of silica can be calculated as a function of $\mathrm{pH}$, as presented in Figure 2, which for

111 simplicity considers only three main forms of dissolved species: $\mathrm{Si}(\mathrm{OH})_{4}, \mathrm{H}_{3} \mathrm{SiO}_{4}{ }^{-}$, and

$112 \mathrm{H}_{2} \mathrm{SiO}_{4}{ }^{2-}$. In calcium-free systems, the dissolved silica remains in the solution and can reach

113 high concentrations up to the solubility limit of alkali silicates.

114

115 To study the kinetics of silica dissolution, one can write the dissolution reaction at $\mathrm{pH}>13$ as

116 Eq. 6, considering that the main dissolved specie at this $\mathrm{pH}$ is $\mathrm{H}_{2} \mathrm{SiO}_{4}{ }^{2-}$ :

117

$$
2 \mathrm{OH}^{-}+\mathrm{SiO}_{2(\mathrm{~s})} \stackrel{\mathrm{k} 1 \text { and k-1 }}{\longleftrightarrow}\left(\mathrm{H}_{2} \mathrm{SiO}_{4}^{2-}\right)_{\mathrm{aq}}
$$

118

119 The rate of $\mathrm{SiO}_{2}$ (glass) dissolution can then be written as:

120

$$
\begin{aligned}
\mathrm{r}=\frac{\mathrm{d}\left[\mathrm{SiO}_{2(\mathrm{~s})}\right]}{\mathrm{dt}} & =\frac{1}{2} \frac{\mathrm{d}\left[\mathrm{OH}^{-}\right]}{\mathrm{dt}}=\frac{\mathrm{d}\left[\mathrm{H}_{2} \mathrm{SiO}_{4}^{2-}\right]_{\mathrm{aq}}}{\mathrm{dt}}=\mathrm{k}_{1}\left[\mathrm{SiO}_{2(\mathrm{~s})}\right]\left[\mathrm{OH}^{-}\right]^{2}-\mathrm{k}_{-1}\left[\mathrm{H}_{2} \mathrm{SiO}_{4}^{2-}\right] \\
& =\mathrm{k}_{1}\left[\mathrm{SiO}_{2(\mathrm{~s})}\right]\left[\mathrm{OH}^{-}\right]^{2}\left(1-\frac{\mathrm{Q}}{\mathrm{K}}\right)
\end{aligned}
$$


122 Where $\mathrm{k}_{1}$ and $\mathrm{k}_{-1}$ are the kinetic constants of the forward and reverse reactions, respectively, and $\left[\mathrm{SiO}_{2(\mathrm{~s})}\right]$ is the mass or surface area of solid glass. The equilibrium constant $\mathrm{K}$ and the reaction quotient $\mathrm{Q}$ are defined as:

125

126

$\mathrm{K}=\frac{\left\{\mathrm{H}_{2} \mathrm{SiO}_{4}^{2-}\right\}_{\mathrm{EQ}}}{\left\{\mathrm{SiO}_{2(\mathrm{~s})}\right\}_{\mathrm{EQ}}\left\{\mathrm{OH}^{-}\right\}_{\mathrm{EQ}}^{2}}$

$$
\mathrm{Q}=\frac{\left\{\mathrm{H}_{2} \mathrm{SiO}_{4}^{2-}\right\}_{\mathrm{aq}}}{\left\{\mathrm{SiO}_{2(\mathrm{~s})}\right\}_{s}\left\{\mathrm{OH}^{-}\right\}^{2}}
$$

127

128 Where the subscript EQ. indicates equilibrium conditions, and the terms in \{\} represents activity of the ions. According to Eq. 7, the partial order of the reaction is assumed to be 2 for $\mathrm{OH}^{-}$and 1 for $\mathrm{SiO}_{2(\mathrm{~s})}$ and $\mathrm{H}_{2} \mathrm{SiO}_{4}{ }^{2-}$. However, in a more general case, the partial reaction order could be considered as $\alpha, \beta$ and $\gamma$ as shown in Eq. 10:

132

$$
\mathrm{r}=\mathrm{k}_{1}\left\{\mathrm{SiO}_{2(\mathrm{~s})}\right\}^{\alpha}\left\{\mathrm{OH}^{-}\right\}^{\beta}\left(1-\frac{\mathrm{Q}}{\mathrm{K}}\right)^{\gamma}
$$

134 According to Eq. 10, the rate of glass dissolution is related to the $\mathrm{pH}$ of the solution and the

135 distance from the equilibrium. In this equation, the surface area of glass can be considered as a proxy for $\left[\mathrm{SiO}_{2(\mathrm{~s})}\right]$, which remains constant during the experiments performed in this study.

\subsection{Solid products and the role of calcium during glass dissolution}

139 In the presence of dissolved $\mathrm{Ca}$, aqueous silica ions are linked to form poly-metal-silicates 140 (e.g., Eq. 11) [22,24,26]:

141

$$
2 \mathrm{H}_{3} \mathrm{SiO}_{4}^{-}+\mathrm{Ca}^{2+} \rightarrow \mathrm{H}_{6} \mathrm{Ca} \mathrm{Si}_{2} \mathrm{O}_{8}
$$


143 Once a nucleus of critical size is formed, it grows to nano-colloidal silica (sol) through

144 further condensation. Aggregation of these colloidal particles forms larger metal silicate

145 structures, such as gels or precipitates [26]. This mechanism is similar to dissolution of $\mathrm{C}_{2} \mathrm{~S}$

146 and $\mathrm{C}_{3} \mathrm{~S}$ and precipitation of C-S-H, as discussed by $[27,28]$.

147

148 In addition to the sol-gel sequence mentioned above, the surface of glass can be altered into a 149 gel layer. This hydrated surface layer can form as a result of ion exchange (leaching) between 150 glass and solution or by breaking some (not all) of the siloxane (Si-O) bonds through 151 hydrolysis [18]. The gel layer (also known as the "passivating reactive interphase, or PRI") 152 can limit the diffusion of ions between glass and the solution, and as such, reduce the 153 corrosion rate of the underlying glass [29]. Several studies, primarily within the domain of 154 nuclear waste glass research, have looked at formation, composition, and properties of the 155 PRI as a function of the glass and solution compositions, temperature, and glass surface area 156 to solution volume ratio $(\mathrm{SA} / \mathrm{V})[30,31,32,33,34,35,36,37,38]$. However, most of these 157 studies are based on corrosion of complex multi-oxide nuclear glasses (containing primarily

$158 \mathrm{Si}, \mathrm{B}, \mathrm{Na}$, and $\mathrm{Al}$ ) in groundwater (typically $\mathrm{pH}<10$ ). As such, their findings may or may not 159 be directly applicable to simpler glasses, such as those found in concrete SCMs and aggregates, and at much higher alkalinities.

161

162 It has been reported that $\mathrm{Ca}$ can reduce the rate of glass alteration, either temporarily or 163 permanently. Oka et al. [36,37] reported an inhibitory effect of $\mathrm{Ca}, \mathrm{Zn}$ and $\mathrm{Al}$ on corrosion 164 rate of fused silica glass in $0.5 \mathrm{M}$ and $1.5 \mathrm{M} \mathrm{NaOH}$ solutions, and attributed this to formation 165 of a protective barrier layer. Snellings [10,34] studied dissolution of synthetic Ca-Al-Si 166 glasses at $20{ }^{\circ} \mathrm{C}$ and $\mathrm{pH} \approx 13$, and confirmed that $\mathrm{Ca}$ in the solution can significantly reduce 167 the initial rate of glass corrosion. By studying borosilicate and nuclear glasses, Chave et al. 
168 [31] reported that the passivating properties of PRI are enhanced when it contains calcium

169 (originating either from the glass or the solution). Rajmohan et al. [39] studied nuclear glass

170 corrosion at $\mathrm{pH}=7$ to 10 , and reported that $\mathrm{Ca}$ was retained in PRI, preferably over $\mathrm{Na}$, and

171 this effect increased with the $\mathrm{pH}$. Further, diffusion coefficient of PRI was lowered by

172 increasing $\mathrm{pH}$. Utton et al. [2,35] measured the dissolution rate of powdered borosilicate glass

173 in saturated $\mathrm{Ca}(\mathrm{OH})_{2}$ solution, and observed a reduced dissolution rate due to formation of

174 calcium borate and other $\mathrm{Ca}$ - and $\mathrm{Mg}$-bearing precipitates on the surface of glass.

175

176 By studying borosilicate glasses, Mercado-Depierre et al. [32] illustrated that both $\mathrm{pH}$ and the

177 glass surface area to solution volume ratio $(\mathrm{SA} / \mathrm{V})$ affect the nature of $\mathrm{Ca}$ interaction with

178 silica surface in a corrosion experiment. At high $\mathrm{pH}(\approx 11.7)$ and low $\mathrm{SA} / \mathrm{V}, \mathrm{Ca}$ is integrated

179 into PRI and mitigates glass corrosion. However, at high SA/V, alteration of glass is

180 accelerated in the presence of $\mathrm{Ca}$, due to conversion of glass to $\mathrm{C}-\mathrm{S}-\mathrm{H}$ with $\mathrm{Ca} / \mathrm{Si} \approx 0.85$

181 (similar to pozzolanic reaction). Fournier at el. [33] stated that although the rate of glass

182 alteration drops with time due to formation of PRI, a resumption of alteration rate is possible.

183 This is more probable in systems with high SA/V (e.g., confined media), and is due to 184 formation of secondary crystalline phases such as zeolite (in systems containing Al) and C-S-

$185 \mathrm{H}$ (in systems containing Ca) $[32,40]$.

186

$187 \quad 2.4$. Use of soda lime glass in concrete

188 Recycled soda-lime glass (from recycling glass bottles and window plates) has been 189 considered in past studies as a potential pozzolan $[1,41,42,43,44,45]$ or aggregate $[46,47,48]$

190 for concrete. Rajabipour et al. [49,50] showed that glass aggregates larger than approximately

$1910.6 \mathrm{~mm}$ undergo deleterious ASR, which originates through pre-existing internal microcracks

192 of crushed glass particles (Figure 3a). The surface of glass aggregates exposed to cement 
193 paste was apparently immune to ASR and was primarily subjected to a pozzolanic reaction

194 (Figure 3b). The internal microcracks originated during glass crushing before its use in

195 concrete, and were found to be more extensive in larger particles [51]. It was also confirmed

196 that these residual cracks could be removed through annealing of crushed glass cullet to

197 mitigate ASR [51]. Similarly, when using crack-free soda-lime glass beads in portland

198 cement mortars, no ASR was observed (Figure 3c). An intriguing question is why glass

199 particles do not undergo ASR at their surface, and what role, if any, the presence of solid

$200 \mathrm{Ca}(\mathrm{OH})_{2}$ at the glass-cement paste interface plays in preventing ASR. Interestingly, when

201 soda-lime glass aggregates were used in alkali-activated fly ash mortars, which do not form

202 solid $\mathrm{Ca}(\mathrm{OH})_{2}$, ASR gel was observed both within the interior and at the surface of glass

203 aggregates (Figure 3d). It should be noted that soda-lime glass contains approximately 7 to $10 \% \mathrm{CaO}$, which supplies Ca necessary for formation of ASR gel.

\section{Materials and Experimental Methods}

207 This study was divided in two phases (Table 1). First, the kinetics of glass dissolution in 208 highly alkaline $\mathrm{NaOH}$ solutions $(12.0<\mathrm{pH}<14.9)$ in the absence or presence of $\mathrm{Ca}$ was 209 evaluated. In the second phase, solid products that form as a consequence of soda-lime glass

210 dissolution were characterized. Two types of silicate glasses were studied: a soda-lime (SL)

211 and a fused silica (FS) glass. Table 2 shows the oxide composition of these two glasses. Glass

212 dissolution experiments were conducted in static batch reactors, where two SL glass slides

$213(50 \times 75 \times 1 \mathrm{~mm})$ were submerged in $\mathrm{NaOH}$ solutions in properly sealed plastic containers to

214 obtain $\mathrm{SA} / \mathrm{V}=45 \mathrm{~m}-1$. Attempts were made to minimize carbonation by preparing the

215 solutions in a $\mathrm{N}_{2}$ purged glove box, and minimizing the exposure of the materials to the

216 atmosphere. The setups were stored in an oven at $60^{\circ} \mathrm{C}$ or otherwise noted temperatures. The

217 fused silica slides had smaller width $(25 \mathrm{~mm})$; however, the SA/V was maintained at $45 \mathrm{~m}^{-1}$. 
218 Reagent $\mathrm{NaOH}$ and $\mathrm{Ca}(\mathrm{OH})_{2}$ were mixed with deionized (DI) water in preparation of the 219 solutions.

220

\subsection{Kinetics of silica glass dissolution in $\mathrm{NaOH}$ solutions}

\subsubsection{Effect of $\mathrm{NaOH}$ concentration (or $\mathrm{pH}$ ) on dissolution rate}

223 As the first parameter, the effect of $\mathrm{NaOH}$ concentration (from 0.01 to $8.0 \mathrm{M}$ ) on dissolution rate of SL glass was studied. After 7 days, slides were removed from the solutions, thoroughly washed with water, dried, and weighed using a scale with the precision of 0.0001 g, to quantify the mass loss for each slide. As discussed below, after washing, no residual precipitates remained on the surface of glass. As such, mass measurements represent the true mass loss of glass due to alkaline corrosion. After finding the most corrosive $\mathrm{NaOH}$ solution (i.e., 1.0 $\mathrm{M}$ as will be seen in the following sections), the remaining experiments were performed with this solution (Table 1).

\subsubsection{Effect of temperature on dissolution rate}

233 SL slides were submerged in $1 \mathrm{M} \mathrm{NaOH}$ solutions at $20^{\circ} \mathrm{C}, 40^{\circ} \mathrm{C}, 60^{\circ} \mathrm{C}$ and $80^{\circ} \mathrm{C}$. The mass loss values were measured up to 210 days in experiments at $20^{\circ} \mathrm{C}$ and $40^{\circ} \mathrm{C}$, up to 46 days at $60^{\circ} \mathrm{C}$, and up to 14 days at $80^{\circ} \mathrm{C}$. The activation energy of SL glass dissolution in $1 \mathrm{M} \mathrm{NaOH}$ solution was determined using the Arrhenius equation (Eq. 12); where $\mathrm{r}$ is the mass loss rate, $\mathrm{A}$ is a pre-exponential factor, $\mathrm{Ea}$ is the activation energy of dissolution, $\mathrm{R}$ is the universal gas constant $\left(8.314 \mathrm{~J} / \mathrm{mol}^{\circ} \mathrm{K}\right)$, and $\mathrm{T}$ is the absolute temperature.

239

$$
\mathrm{r}=\mathrm{A} \mathrm{e}^{\frac{-\mathrm{Ea}}{\mathrm{RT}}}
$$

\subsubsection{Effect of dissolved Ca on dissolution rate}


242 To examine how the presence of calcium influences the rate of glass dissolution, the 243 following four systems were studied:

244 1. SL glass in $1 \mathrm{M} \mathrm{NaOH}$ solution, without added $\mathrm{Ca}(\mathrm{OH})_{2}$ (labeled "soda-lime No-CH"),

245 2. SL glass in $1 \mathrm{M} \mathrm{NaOH}$ solution, under saturated with respect to $\mathrm{Ca}(\mathrm{OH})_{2}$ (labeled 246 “soda-lime US-CH”),

247 3. SL glass in $1 \mathrm{M} \mathrm{NaOH}$ solution, saturated with and also containing excess residual $\mathrm{Ca}(\mathrm{OH})_{2}$ solid powder in the reactor (labeled "soda-lime SS-CH"),

4. FS glass in $1 \mathrm{M} \mathrm{NaOH}$ solution without $\mathrm{Ca}(\mathrm{OH})_{2}$ (labeled "fused silica No-CH").

The "fused silica No-CH" system contained practically no calcium. The "soda-lime No-CH" system only contained calcium that was contributed by dissolution of the SL glass structure (7.8\% $\mathrm{CaO})$. The "soda-lime US-CH" system was prepared by filtering a $\mathrm{Ca}(\mathrm{OH})_{2}$ saturated $1 \mathrm{M} \mathrm{NaOH}$ solution, and diluting it with adding more $1 \mathrm{M} \mathrm{NaOH}$ solution. For "soda-lime SS-CH" system, $1.0 \mathrm{~g}$ of $\mathrm{Ca}(\mathrm{OH})_{2}$ powder was mixed in 0.33 liters of $1 \mathrm{M} \mathrm{NaOH}$ solution. Since the solubility of $\mathrm{Ca}(\mathrm{OH})_{2}$ in $1 \mathrm{M} \mathrm{NaOH}$ is very low (approximately $0.45 \mathrm{mM}=18 \mathrm{mg} / \mathrm{l}$ ), most of the $\mathrm{Ca}(\mathrm{OH})_{2}$ precipitated to maintain a solution saturated with $\mathrm{Ca}(\mathrm{OH})_{2}$ throughout the experiment. Mass loss of glass slides in these four systems was measured after 7, 14, 21 and 28 days of exposure to the solutions. This led to 16 independent reactors to avoid mass loss measurement at each age to interfere with measurements at later ages for the same system.

Exposure of SL glass to $1 \mathrm{M} \mathrm{NaOH}$ solution resulted in formation of altered layer and solid products on the surface of glass that could be easily removed under running water to leave a transparent surface (Figure 4-left). However, in the presence of added $\mathrm{Ca}(\mathrm{OH})_{2}$ (i.e., "soda-

266 lime SS-CH" system) the altered layer (rich in Ca) was strongly-bonded, and could not be 
removed by washing with water, and therefore left a translucent surface (Figure 4-right). This surface layer could interfere with mass loss measurements to correctly quantify the dissolution rates. To address this challenge, after the dissolution experiment, the surface layer was removed by dissolving it in $6.0 \mathrm{M}$ hydrochloric acid. SEM analysis confirmed that submerging the slides in acid for $1 \mathrm{~h}$ completely removed the precipitated layer. This practice was checked separately on a plain SL glass to ensure that the substrate glass is not losing mass during exposure to the acid. For the "fused silica No-CH" system, no corrosion products were formed and the surface of the slides remained transparent (Figure 4-middle). However, during the $3^{\text {rd }}$ week of the exposure, the edges of the slides started to crack and scale. This 276 influences the mass loss results, which is discussed later.

\subsubsection{Analysis of the solution chemistry}

The alkaline solution surrounding glass slides in the four systems introduced in section 3.1.3 was periodically sampled and filtered using $0.2 \mu \mathrm{m}$ PTFE filter syringes. The solution $\mathrm{pH}$ was measured by acid titration and was found to remain near 14.0 throughout the course of the experiment. Also, the concentration of $\mathrm{Ca}$ and $\mathrm{Si}$ were measured using inductively coupled plasma atomic emission spectrometry (ICP-AES) up to 80 day of exposure. Prior to measurement, ICP samples were diluted $10 \times$ using $2 \% \mathrm{HNO}_{3}$ solution.

\subsection{Characterization of the corrosion products}

$287 \quad$ 3.2.1. SEM/EDS analysis

288 Scanning electron microscopy coupled with energy dispersive spectroscopy (SEM/EDS) was employed to analyze the corrosion products of SL glass. After 1 and 2 weeks of exposure to 1 $\mathrm{M} \mathrm{NaOH}$ solution at $60^{\circ} \mathrm{C}$, glass slides were removed from the solutions and dried under 
292 broken and a small piece was placed on a vertical sample holder for cross-sectional analysis.

293 In addition, the products were collected from the surface of SL slides and gently spread on a

294 carbon tape. High vacuum field emission SEM (FEI NanoSEM 630) was employed to study 295 the microstructure and composition of these products. EDS data was generated on at least 10 296 area zones or spots for each observed feature.

297

298 Furthermore, to ensure that the observed microstructural features were not the artifacts of 299 drying or high vacuum conditions in SEM, the products in "soda-lime No-CH" system were 300 also studied in a low vacuum mode of an environmental SEM (FEI Quanta 200). SL slides 301 were removed from the solutions, promptly broken and a piece was placed horizontally inside

302 the ESEM chamber, which was later adjusted to one of two conditions: " $\mathrm{T}=20^{\circ} \mathrm{C}$ and $303 \mathrm{RH}=95 \%$ " or " $\mathrm{T}=25^{\circ} \mathrm{C}$ and $\mathrm{RH}=80 \%$ ". The surface of the glass piece was slightly disturbed 304 in randomly selected zones to better observe the microstructure of the corrosion products.

\subsubsection{XRD analysis}

307 Corrosion products of soda-lime glass after exposure to $1 \mathrm{M} \mathrm{NaOH}$ solution (with and without $\mathrm{Ca}(\mathrm{OH})_{2}$ ) were analyzed using powder x-ray diffraction (XRD). After 1, 2 and 3 weeks of exposure, corrosion products were collected from vacuum-dried slides, ground into a powder, and placed on a zero background zirconium holder. Diffraction patterns were

311 collected using a PANalytical X'Pert Pro MPD horizontal goniometer with $\mathrm{Cu}-\mathrm{K} \alpha$ radiation, 312 and fixed slit incidence and diffracted optics $\left(0.5^{\circ}\right.$ anti-scatter, $0.02 \mathrm{~mm}$ nickel filter). Data 313 was collected at $45 \mathrm{kV}$ and $40 \mathrm{~mA}$ from $5-70$ degrees $2 \theta$ for duration of $\sim 30 \mathrm{~min}$. For the 314 specimen "soda-lime No-CH" at 2 weeks, a beam knife was used to improve the reflectivity 315 curves, specifically at low $2 \theta$ angles. Resulting patterns were analyzed using Jade software 316 (MDI, Livermore, CA). 
$318 \quad \underline{3.2 .3 .} \mathrm{N}_{2}$ adsorption porosity measurement

319 Nitrogen absorption analysis was employed to quantify the porosity, pore size distribution, 320 and BET surface area of the corrosion surface products after 1 week of the experiment. A 321 comparison was made between the products that formed in the absence or presence of

$322 \mathrm{Ca}(\mathrm{OH})_{2}$ in the solution ("soda-lime No-CH" vs. "soda-lime SS-CH”). Corroded glass slides 323 were rinsed gently using DI water, and dried under vacuum for 7 days. Next, the corrosion products were carefully collected from the surface of each slide using a blade and placed inside BET chamber. $\mathrm{N}_{2}$ adsorption isotherms were obtained using Micromeretics ASAP 2020 instrument.

\subsubsection{TEM analysis of corroded glass surface}

329 To better understand the mechanism of glass dissolution and to study the interface between 330 the glass and corrosion products, thin sections were prepared for transmission electron 331 microscopy (TEM), using focused ion beam (FIB) method. A soda-lime No-CH slide, after 332 corrosion for 7 days in $1 \mathrm{M} \mathrm{NaOH}$ solution was vacuum dried. Inside a SEM-FIB chamber, staring from the top of the corrosion products, a square area was chosen for ion milling. First, a thin layer of platinum $(\mathrm{Pt})$ was deposited as a line in the middle of the square area to protect the specimen directly underneath the Pt-line from ion milling. Next, using $\mathrm{Ga}^{+}$ions, two

336 trenches were milled at the two sides of the Pt line to create a vertical slab composed of the

337 Pt-deposit, corrosion products, and the glass substrate. By progressively reducing the ion 338 beam's current and spot size, the slab was milled to a thin section of approximately 50nm.

339 The process is shown in Figure 5. Using a manipulator needle, the thin section was placed on 340 a TEM grit. Due to the challenges involved in this approach (will be discussed later), the 341 second specimen (soda-lime SS-CH slide) was prepared slightly differently. Glass slide was 
342 dried and broken after two weeks of exposure and FIB was initiated from the cross section of

343 glass as shown in Figure 5c. TEM imaging was performed using a JEOL 2010F TEM

344 operated at $200 \mathrm{kV}$.

346 4. Results

\section{4.1. Kinetics of silica glass dissolution}

$348 \quad$ 4.1.1. Effect of $\mathrm{NaOH}$ concentration on dissolution rate

349 Figure 6 shows that increasing $\mathrm{NaOH}$ concentration up to $1 \mathrm{M}$ resulted in an increased rate of

350 SL glass dissolution ( $\mathrm{mg} / \mathrm{cm}^{2}$.day). However, for higher molarities, the rate of dissolution decreased. Tarnopol and Junge [52] also observed that dissolution rate of SL glass was maximized at an intermediate concentration for $\mathrm{NaOH}$ and $\mathrm{Na}_{2} \mathrm{CO}_{3}$ solutions of approximately 1.3 M. It should be noted that in this SA/V system, dissolution of SL slides was found to continue at a nearly constant rate (Figure 7a) until the entire glass slide is consumed. According to Figure 6 , for $\mathrm{pH}<14$, the logarithm of the dissolution rate followed a linear trend versus the $\mathrm{pH}$ of the solution:

$$
\log \left[\mathrm{r} \equiv \text { SL glass dissolution rate }\left(\mathrm{mg} / \mathrm{cm}^{2} \text {.day }\right)\right]=0.196 \mathrm{pH}-3.481
$$

360 According to Eq. 10, the slope of this line is the partial order of dissolution reaction with respect to $\left[\mathrm{OH}^{-}\right]: \beta \approx 0.20$. Note that in Eq.10, the value of $Q / K$ approaches zero since the concentration of the dissolved silica at this age $(7 \mathrm{~d})$ was much below the saturation limit at this $\mathrm{pH}$ (compare Figure 9a and 2). In addition, the surface area of glass slides $\left[\mathrm{SiO}_{2(\mathrm{~s})}\right]$ remained approximately constant during the experiment. 
366 The observation that SL glass dissolution rate decreased at very high $\mathrm{pH}>14$ may be

367 attributed to the increased negative electric charge on the glass surface, due to formation of

$368 \equiv$ Si-O ${ }^{-}$sites. In addition, $\mathrm{H}_{2} \mathrm{SiO}_{4}{ }^{2-}$ ions would accumulate near the glass surface, which repel

369 the attacking hydroxyl ions. Another hypothesis is that at very high $\mathrm{NaOH}$ concentrations,

370 overcrowding and strong ion-ion interactions could decrease the affinity of the solution to

371 dissolve silicates. In such concentrated solutions, water activity is decreased and there may

372 not be enough water molecules to fully hydrolyze the ionic species; and this may hamper the

373 dissolution rate. This phenomenon also manifests itself in an increased activity coefficient of

$374 \mathrm{OH}^{-}$ions above $\mathrm{pH}=14$ (Figure 6), as calculated based on the Bromley's model for strong

375 electrolyte solutions [53]. Finally, due to the static nature of the experiment, and low self-

376 diffusion coefficients of ions in concentrated solutions [54], dissolved silicates accumulate in

377 the vicinity of glass surface. This reduces the glass dissolution rate by intensifying the

378 previous mechanisms. These hypotheses need further verification to draw firm conclusions.

$380 \quad$ 4.1.2. Effect of temperature on dissolution rate

381 Figure 7a shows that the mass loss of SL glass changes approximately linearly with respect to 382 time (constant rate), which agrees with Eq. 10. This is due to the low concentration of 383 dissolved silica comparing to the saturation limit; i.e., $\mathrm{Q} / \mathrm{K} \approx 0$ (compare Figures $9 \mathrm{a}$ and 2), 384 and the fact that glass surface area $\left(\left[\mathrm{SiO}_{2(\mathrm{~s})}\right]\right)$ and $\mathrm{pH}$ remained constant during the corrosion 385 experiment.

387 Using the Arrhenius equation (Eq. 12), the activation energy of SL glass dissolution in $1 \mathrm{M}$ $388 \mathrm{NaOH}$ solution was calculated as $87.5 \mathrm{~kJ} \mathrm{~mol}^{-1}$ (Figure $7 \mathrm{~b}$ ). This relatively high value of 389 activation energy indicates that the dissolution is a chemically-controlled surface reaction, 390 and formation of a surface corrosion products layer did not impose a diffusion barrier against 
391 dissolution of SL glass in No-CH system. Activation energy of dissolution is a pH-dependent parameter, which for example, was reported to vary from 43 to $96 \mathrm{~kJ} . \mathrm{mol}^{-1}$ for dissolution of quartz at $\mathrm{pH}=4$ and 11, respectively [55]. Frugier et al. [18] reported an activation energy of

$39476 \mathrm{~kJ} \mathrm{~mol}^{-1}$ for dissolution of SON68 nuclear glass at temperatures ranging from 25 to $100^{\circ} \mathrm{C}$ 395 and $\mathrm{pH}=6$ to 10 .

\subsubsection{Effect of dissolved Ca on dissolution rate}

398 The presence of dissolved Ca had a remarkable impact on reducing the dissolution rate of silica glass at high $\mathrm{pH}$. Figure 8a compares the dissolution mass loss of SL glass in $1 \mathrm{M}$

$400 \mathrm{NaOH}$ solution that was saturated with $\mathrm{Ca}(\mathrm{OH})_{2}$ versus the solution that did not contain $401 \mathrm{Ca}(\mathrm{OH})_{2}$. It should be reminded that in the SS-CH reactor, a strongly bonded layer of corrosion products formed on the surface of glass slides during the experiment; but this layer was removed using $\mathrm{HCl}$ acid prior to mass measurements. As noted before, SEM imaging and parallel treatments of virgin glass confirmed that the acid treatment employed, effectively dissolved the corrosion product layer without dissolving the substrate glass. Comparison of the glass dissolution between the two reactors (Figure 8a) show that the dissolution rate was initially similar in both reactors. However after 3 days, the dissolution rate was drastically reduced in the SS-CH reactor. This is likely attributed to the formation of a dense and protective layer on the surface of glass. The characterization results provided in section 4.2 identify this layer to be primarily C-S-H. According to Chave et al [31] calcium from the solution enhances condensation of siloxane bonds and modifies the passivating property of

412 the altered layer on the glass surface.

414 As seen in Figure 8b, the SL dissolution rate in the US-CH reactor was similar to that of the 415 No-CH reactor. The Ca concentration in both reactors was likely to be insufficient (and was 
416 rapidly consumed; confirmed by ICP-AES) to form a dense protective layer on the surface of 417 glass. Figure $8 \mathrm{~b}$ also shows that dissolution of fused silica slides appeared to be similar to

418 that of SL glass up to 14 days. However after this time, edge cracking and scaling started to 419 appear on the slides (Figure 4-middle), which increased their mass loss. As such, mass 420 measurements of FS slides were only reliable up to 14 days. The reason for this scaling in 421 unclear, but might be due to the procedure used for cutting FS slides that resulted in residual 422 stresses and micro-cracks at the edges. These microcracks could propagate and scale off under the alkaline attack.

\subsubsection{The solution chemistry}

426 According to Figure 9a, No-CH and US-CH systems showed very similar values of silica release into the solution. An approximate mass balance calculation using glass slide mass loss and ICP data suggests that more than $80 \%$ of the dissolved Si went into the solution, and the rest was consumed in formation of solid corrosion products. On the other hand, in the SS-CH system, concentration of $\mathrm{Si}$ in the solution was measured to be very low, which is likely due to its reaction with $\mathrm{Ca}$ to from $\mathrm{C}-\mathrm{S}-\mathrm{H}$ on the surface of glass slide. The fused silica $\mathrm{No}-\mathrm{CH}$ system showed the highest Si concertation in the solution, which is reasonable because: (a) FS has higher $\mathrm{SiO}_{2}$ content than SL glass, resulting in a higher Si release at the same glass dissolution rate, (b) $\mathrm{Si}$ in FS reactor remains entirely in the solution due to the absence of $\mathrm{Ca}$ and lack of precipitate formation, and (c) FS glass experienced an increased surface area due to edge scaling beyond 14 days of corrosion. solution, Ca concentration remained near saturation due to the presence of solid $\mathrm{Ca}(\mathrm{OH})_{2}$ in 440 the reactor. The small decrease in Ca concentration with time may be due to a slight increase 
441 in the $\mathrm{pH}$ of the solution, which reduces the solubility of $\mathrm{Ca}(\mathrm{OH})_{2}$. In No-CH and US-CH

442 soda-lime reactors, similar trends of initially increasing Ca concertation due to dissolution of

443 SL glass, followed by decreasing Ca concertation was observed. The reduction could be the

444 result of reaction with dissolved silica to form solid products.

\section{4.2. Characterization of the corrosion products}

\section{4.2.1. SEM/EDS results}

448 Two types of corrosion products were observed to form on the surface of glass slides in the 449 "soda-lime No-CH" reactors (Figure 10a). One type appeared as ordered pillars extending 450 perpendicular to the surface of glass, and the other being a more porous and randomly 451 oriented products, forming on top of the ordered layer. The $\mathrm{Ca} / \mathrm{Si}$ ratio in each phase is also presented (measured by EDS for solid phases and ICP for the solution). It was observed that the corrosion products had 6 to 9 times higher $\mathrm{Ca} / \mathrm{Si}$ than the source SL glass. In combination with the ICP results (Figure 9) and considering that SL glass is the only source of Ca in this reactor, it can be argued that the majority of $\mathrm{Si}(>80 \%)$ from the dissolving glass was passed into the solution, while Ca was bound in the solid products.

Figure $10 \mathrm{~b}$ shows the morphology of the ordered products, when collected from the surface of a rinsed SL slide. It can be observed that the ordered layer is highly porous, with a

460 honeycomb morphology. Note that the top surface of the ordered products seen in Figure $10 \mathrm{~b}$ 461 was facing the glass substrate. Figure 10c shows the microstructure of the disordered 462 products. These have a morphology and $\mathrm{Ca} / \mathrm{Si}$ close to that of tobermorite (a crystalline form 463 of C-S-H) [56,57], and were identified as such by XRD analysis (section 4.2.2). 
465 Formation mechanism of the glass corrosion products deserves attention. The products could 466 precipitate from the solution or could form by an in-situ alteration of the glass surface [14,

$46730]$. The disordered nature of the outer products and the fact that they have formed on top of 468 the ordered products suggest that these have likely precipitated from the solution. This agrees 469 with the initial increase and the subsequent decrease of $\mathrm{Ca}$ concentration in the solution 470 (Figure 9b). They resemble the outer C-S-H products formed during cement hydration. The ordered products, however, are more likely to be the result of in-situ transformation of glass or dissolution-precipitation reactions at the nano-scale. This is discussed further by the TEM results. It is likely that the boundary between the ordered and disordered products was the 474 initial surface of soda-lime glass.

Figures 11 (a) and (b) show the microstructure of the corrosion products, imaged by ESEM at $\mathrm{T}=20^{\circ} \mathrm{C}-\mathrm{RH}=95 \%$ and $\mathrm{T}=25^{\circ} \mathrm{C}-\mathrm{RH}=80 \%$, respectively. The right side of Figure $11 \mathrm{a}$ shows the top view of the disordered precipitates. The left side of the image shows the surface that was disturbed using a sharp blade to reveal the ordered products underneath. Figure $11 \mathrm{~b}$ also

480 shows the microstructure of the products, confirming that these products formed during corrosion of the glass inside the $\mathrm{NaOH}$ solution and not as a result of drying or high vacuum SEM.

484 In the reactors saturated with portlandite (SS-CH), both ordered and disordered corrosion 485 products were also formed. However, unlike the No-CH reactors, the ordered products had 486 high $\mathrm{Ca}$, appeared to be denser (also confirmed by the $\mathrm{N}_{2}$ adsorption results), and were strongly bonded to the substrate glass. Figure 12 shows a SEM image and x-ray maps of Si, $488 \mathrm{Ca}$, and $\mathrm{Mg}$ within the substrate SL glass and the ordered surface layer. The disordered 489 precipitates were rinsed away using DI water prior drying and imaging. 
491 Table 3 presents the elemental composition of the corrosion products of SL glass in the 492 presence or absence of calcium. It should be noted that since these EDS data were not 493 acquired on flat surfaces, the results should be treated qualitatively rather than drawing firm 494 quantitative conclusions. Based on the EDS results, the corrosion products are primarily 495 hydrated calcium (and possibly magnesium) silicates, with smaller contents of $\mathrm{Na}$ and $\mathrm{Al}$. 496 ICP of $\mathrm{Ca}$ and $\mathrm{Mg}$ (not included) showed a very low concentration of these elements in the 497 solution (except for the [Ca] in $\mathrm{SS}-\mathrm{CH}$ reactor), suggesting that both $\mathrm{Ca}$ and $\mathrm{Mg}$ react 498 preferentially with the dissolved silica to form the solid corrosion products. It is more 499 meaningful to compare the relative ratio of the elements (e.g., $\mathrm{Ca} / \mathrm{Si}$ ), rather than their 500 absolute values. In the No- $\mathrm{CH}$ reactor, the average $\mathrm{Ca} / \mathrm{Si}$ of all corrosion products was 1.05 501 on a weight basis. In comparison, corrosion products in the $\mathrm{SS}-\mathrm{CH}$ reactor, had a considerably higher $\mathrm{Ca} / \mathrm{Si}(1.84)$, and considerably lower $\mathrm{Na} / \mathrm{Si}(0.05$ vs. 0.22$)$ and $\mathrm{Mg} / \mathrm{Si}$ (0.31 vs. 0.59 ). Due to its divalent nature, $\mathrm{Ca}$ acts as a pseudo network former and increases

504 the stability of hydrated silicates [6]. On the other hand, $\mathrm{Na}$ is monovalent and breaks up the 505 silica network by forming non-bridging oxygens. As a result, hydrated calcium silicates with higher $\mathrm{Ca}$ and lower $\mathrm{Na}$ have been suggested to be stronger, stiffer, and more volumetrically stable $[58,59,60,61]$. This is likely the reason that the corrosion products layer in the SS-CH reactor was strongly bonded to the substrate glass, while the products in the No-CH reactor could be easily removed from the glass surface.

\subsubsection{XRD results}

512 Figure 13 shows x-ray diffraction patterns of the corrosion products (mixture of both ordered

513 and disordered) of SL glass in No-CH and SS-CH reactors. The main crystalline phase in the

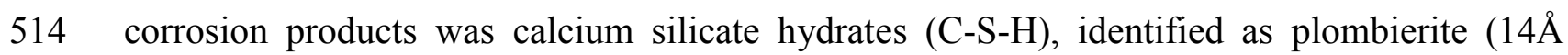


515 tobermorite $\left.\mathrm{Ca}_{5} \mathrm{Si}_{6} \mathrm{O}_{16}(\mathrm{OH})_{2}\right)$ [56,62,63]. The diffuse peak at approximately $2 \theta \sim 7.1^{\circ}$ 516 corresponds to the basal spacing between C-S-H layers, and can be measured as 517 approximately $12.44 \AA$, which is slightly smaller than plomberite (14 $\AA$ ). The interlayer 518 spacing depends on the degree of hydration of C-S-H and temperature [62]. In addition to C519 S-H, brucite $\left(\mathrm{Mg}(\mathrm{OH})_{2}\right)$ was identified as a minor phase. Although no Na-bearing mineral 520 was identified in XRD, it is likely that $\mathrm{Na}$ is absorbed within $\mathrm{C}-\mathrm{S}-\mathrm{H}$. In general, agreement between XRD and EDS results was satisfactory. A phase with corresponding peaks at $11.2^{\circ}$ and $22.4^{\circ}$ could not be identified confidently. An amorphous hump within the $2 \theta$ range of $28-$ $36^{\circ}$ is attributed to the amorphous C-S-H and is more profound in SS-CH system, which is due to the higher Ca content within C-S-H chains [57]. The nature of the corrosion products did not significantly change with time.

\subsection{3. $\mathrm{N}_{2}$ adsorption results}

The BET surface area of the corrosion products in soda-lime SS-CH and No-CH systems were measured as 51.2 and $32.4 \mathrm{~m}^{2} / \mathrm{g}$, respectively. The pore size distributions are shown in

530 Figure 14, suggesting that corrosion products in the SS-CH reactor had lower porosity and smaller pore size. In this reactor, pores smaller than $100 \AA$ constituted more than $85 \%$ of the total volume of the pores, and no pores smaller than $20 \AA$ was measured. For No-CH system, the pores smaller than $100 \AA$ constituted only $32 \%$ of the total volume of the pores. It should

534 be noted that pore size distribution measurements using $\mathrm{N}_{2}$ absorption becomes inaccurate for pore sizes larger that 300 to $400 \AA[64,65]$.

\subsubsection{TEM results}

538 Analysis of the thin sections of the soda-lime No-CH slide, prepared using the first FIB 539 approach (Figure 5a) showed significant damage and extensive re-deposition of $\mathrm{Pt}$ and $\mathrm{Cu}$ on 
540 the specimen. Initiation of ion milling through the porous and weakly bonded corrosion 541 products, made it difficult to obtain a suitable thin section for TEM analysis. In the second

542 FIB approach, which was applied to the soda-lime SS-CH slide, milling was initiated from a 543 cross section of glass (Figure 5c) and the corrosion products were strongly bonded to the 544 glass surface. As such, a much better thin section was obtained.

546 Figure 15 is a low magnification TEM image, showing the glass substrate and ordered 547 corrosion products in the SS-CH reactor. High resolution TEM imaging (Figure 16) showed a 548 seemingly continuous transition between the glass substrate to the corrosion products, with 549 randomly dispersed crystal nuclei (Figure 16a). There was not a systematic trend for 550 appearance of these crystals and in some cases, small crystalline nuclei were even observed within the glass substrate. By moving within the corrosion products layer away from the glass interface and towards the solution, the number and size of crystals increased considerably 553 (Figure 16b).

\section{Discussion}

556 Congruent dissolution of soda-lime glass in $1 \mathrm{M} \mathrm{NaOH}$ solution and in the absence of added

$557 \mathrm{Ca}(\mathrm{OH})_{2}$ was observed to progress linearly with time at temperatures 20 to $80{ }^{\circ} \mathrm{C}$. This agrees with dissolution regime II (constant rate) introduced by Frugier et al. [18]. It resulted in formation of two overlying corrosion products layers; an ordered layer resulting from in-situ

560 alteration of glass, underneath a disordered layer precipitated from the solution. Both layers

561 contained crystalline C-S-H, whose formation is likely facilitated by the elevated temperature 562 of the experiment $\left(60^{\circ} \mathrm{C}\right)$. The $\mathrm{C}-\mathrm{S}-\mathrm{H}$ had a fairly low $\mathrm{Ca} / \mathrm{Si}(=0.54$ to 0.78 molar ratio), considerable $\mathrm{Na} / \mathrm{Si}$, and a high porosity, resulting in a weak bond to the substrate glass. Due 
to their high porosity, the corrosion products layers in this system did not cause a measurable drop in the glass dissolution rate.

566

567 In this system (soda-lime No-CH with low SA/V), Ca and Si was provided entirely by the 568 glass $(\mathrm{Ca} / \mathrm{Si}=0.09)$. Initially, the congruent dissolution of glass released both $\mathrm{Ca}$ and $\mathrm{Si}$ into 569 the solution (Figure 9b). However, at approximately 3 to 4 days, all of the dissolved Ca 570 precipitated back on the glass surface as C-S-H. Beyond this time, further glass dissolution/alteration only released $\mathrm{Si}$ into the solution while Ca was locally bound, possibly by the ordered corrosion products. Due to the absence of $\mathrm{Ca}$ in the solution $(\mathrm{Ca} / \mathrm{Si}=0.003)$, no ASR gel formed and dissolved Si remains in the solution. However, had glass dissolution occurred within a confined space (e.g., inside an intra-particle crack in Figure 3a or in a high $\mathrm{SA} / \mathrm{V}$ system), the combination of high concentration of dissolved Si and local availability of $\mathrm{Ca}$ at glass surface could form deleterious ASR gel.

In the SS-CH reactor, where the solution was maintained saturated with $\mathrm{Ca}(\mathrm{OH})_{2}$, the available aqueous $\mathrm{Ca}$ reacted with dissolved silica to form a denser, stronger, lower porosity, higher $\mathrm{Ca} / \mathrm{Si}(=1.28$ molar ratio), and negligible $\mathrm{Na} / \mathrm{Si}(=0.06$ molar ratio) $\mathrm{C}-\mathrm{S}-\mathrm{H}$ layer on the surface of glass. This is essentially an inner product pozzolanic C-S-H, which was formed by in-situ transformation of glass as opposed to precipitation from the solution, and as such, does not contain capillary pores (the majority of its pores are $<10 \mathrm{~nm}$ ). The solution remained practically free of dissolved $\mathrm{Si}$ and saturated with $\mathrm{Ca}(\mathrm{OH})_{2}$. The dissolution of glass was significantly reduced but not stopped (in agreement with regime IV (residual rate) of Frugier et al. [18]). This is most likely attributed to the protective nature of the C-S-H layer,

587 providing a diffuse barrier against penetration of $\mathrm{OH}^{-}$and $\mathrm{Na}^{+}$ions. This is why the outside surface of soda-lime glass particles is protected in portland cement systems (Figure 3a to c), 
where the pore solution is locally saturated with $\mathrm{Ca}(\mathrm{OH})_{2}$, but is not protected in binders that do not form $\mathrm{Ca}(\mathrm{OH})_{2}$ (Figure 3d).

As a final comment, we should acknowledge that the barrier nature of the C-S-H layer is a delicate balance. Since the C-S-H layer is not fully impermeable, inward diffusing of $\mathrm{OH}^{-}$, $\mathrm{Na}^{+}$, and $\mathrm{Ca}^{2+}$ from solution towards glass occur simultaneously (note that charge balance must be maintained). Among these, $\mathrm{Ca}$ is the slowest ion [54] and is most likely to be picked up along the way to replace a bound $\mathrm{Na}$ in a low $\mathrm{Ca} / \mathrm{Si} \mathrm{C}-\mathrm{S}-\mathrm{H}$ (this is termed alkali recycling [66]). As $\mathrm{OH}^{-}$reaches and corrodes the glass surface, Ca availability is critical to determine the nature and deleteriousness of the corrosion products. If sufficient $\mathrm{Ca}$ is available, stable and innocuous C-S-H could be formed; but at low Ca concentrations, deleterious ASR gel forms. Since $\mathrm{Ca}$ penetrates slower than $\mathrm{Na}$ and $\mathrm{OH}$, it is possible that in some systems, ASR gel forms underneath an outer C-S-H layer [58]. This C-S-H layer especially mitigates the outward diffusion of dissolved silica and as such, acts as a semi-permeable membrane [19].

603

\section{Conclusions}

- The dissolution rate of soda-lime (SL) glass in $\mathrm{NaOH}$ solutions increases with $\mathrm{pH}$ and is related to $\left[\mathrm{OH}^{-}\right]^{0.2}$ up to $\mathrm{pH}=14$. However, higher $\mathrm{pH}$ results in slower dissolution. Several hypotheses were offered to explain why silica dissolution slows down at very high $\mathrm{pH}$.

- The dissolution rate of SL glass is temperature dependent, and the activation energy of 609 dissolution in $1 \mathrm{M} \mathrm{NaOH}$ was measured as $87.5 \mathrm{~kJ} \cdot \mathrm{mol}^{-1}$.

- Presence of $\mathrm{Ca}$ ions in solution has a remarkable impact on reducing the dissolution rate

611 of SL glass at high $\mathrm{pH}$. This is likely due to formation of a dense, low porosity, high $612 \mathrm{Ca} / \mathrm{Si}$, and strongly bonded C-S-H layer on the surface of glass, which provides a diffuse 613 barrier against penetration and attack of $\mathrm{OH}^{-}$and alkali ions. This is an inner product 
614 pozzolanic C-S-H, and is formed by in-situ transformation of glass as opposed to 615 precipitation from the solution; and as such, does not contain capillary pores (the majority 616 of its pores are $<10 \mathrm{~nm}$ ).

617 - In the absolute absence of $\mathrm{Ca}$, the dissolved silica remains in the solution. However, if 618 there is some, but insufficient, $\mathrm{Ca}$ available in the solution, it is consumed in reaction with 619 the dissolving silica and forms low $\mathrm{Ca} / \mathrm{Si}$ alkali-bearing $\mathrm{C}-\mathrm{S}-\mathrm{H}$ products that are loosely 620 bonded to the surface of silica glass. Due to their porosity, these products cannot protect 621 the glass substrate from further dissolution.

622 - The findings can explain why in portland cement concrete, soda-lime glass aggregates 623 undergo ASR within their intra-particle cracks but not at the glass-cement paste interface.

\section{Acknowledgements}

627 The authors gratefully acknowledge support received from the National Science Foundation 628 (NSF) under Grant No. 1030708 and the CAREER Award No. 1254333, granted to the 629 second author. Any opinions, findings and conclusions or recommendations expressed in this 630 material are those of the authors and do not necessarily reflect the views of the National 631 Science Foundation.

\section{References}

1 H. Maraghechi, M. Maraghechi, F. Rajabipour, C. Pantano, Pozzolanic reactivity of recycled glass powder at elevated temperatures: reaction stoichiometry, reaction products, and effect of alkali activation, Cem Concr Comp 53 (2014) 105-114

2 C.A. Utton, R.J. Hand, P.A. Bingham, N.C. Hyatt, S.W. Swanton, S.J. Williams, Dissolution of vitrified wastes in a high-pH calcium-rich solution." Journal of Nuclear Materials 435 (1-3) (2013) 112-122. 
3 X. Hou, L.J. Struble, R.J. Kirkpatrick, Formation of ASR gel and the roles of C-S-H and portlandite, Cem Concr Res 34 (2004) 1683-1696.

4 M.D.A. Thomas, The role of calcium in alkali-silica reaction, Materials Science of Concrete (Sidney Diamond Symposium), The American Ceramic Society, Ohio, USA, (1998) 325-337.

5 F. Rajabipour, E. Giannini, C. Dunant, J.H. Ideker, M.D.A. Thomas, Alkali-silica reaction: Current understanding of the reaction mechanisms and the knowledge gaps, Cem Concr Res 76 (2015) 130-146.

6 A.K. Varshneya, Fundamentals of Inorganic Glasses, 2nd ed. Academic Press Inc, San Diego, CA, 1994.

7 F. Gaboriaud, D. Chaumont, A. Nonat, B. Hanquet, A. Craeivich, Study of the influence of alkaline ions ( $\mathrm{Li}, \mathrm{Na}$ and $\mathrm{K}$ ) on the structure of the silicate entities in silico alkaline sol and on the formation of the silico-calco-alkaline gel, J. Sol-Gel Sci. Technol. 13 (1-3) (1998) 353-358

8 B.C. Bunker, Molecular mechanism for corrosion of silica and silicate glasses, $\mathrm{J}$ Non-Cryst Solids, 179 (1994), 300-308.

9 R.W. Douglas, T.M. El-Shamy, Reactions of glasses with aqueous solutions, J Amer Cer Soc 50 (1) (1967), 1-7.

10 R. Snellings, Surface chemistry of calcium aluminosilicate glasses. J Am Ceramic Society 98.1 (2015): 303-314.

11 D.E. Clark, M.F. Dilmore, E.C. Ethridge, L.L. Hench, Aqueous corrosion of soda-silica and sodalime-silica glass, J Am Ceram Soc 59 (1976) 62-65.

12 C.G. Pantano, A.E. Clark, L.L Hench, Multilayer corrosion films on bioglass surfaces, J Am Ceram Soc 57 (9) (1974), 412-13.

13 S.C. Kohn, R. Dupree, M.E. Smith, Proton environments and hydrogen-bonding in hydrous silicate glasses from proton NMR, Nature 337 (1989) 539-541.

14 D.E. Clark, B.K. Zoitos, Corrosion of glass, ceramics, and ceramic superconductors: principles, testing, characterization, and applications, Chapter 5, Noyes Publication, USA (1992).

15 H. Scholze, Chemical durability of glasses, J Non-Crys Sol 52 (1-3) (1982), 91-103.

16 H. Scholze, Glass-water interactions, section 1. water and glass, durability, and transport phenomena, J Non-Cryst Sol 102(1988), 1-10.

17 A. Paul, Chemistry of Glasses, $2^{\text {nd }}$ Ed., Chapman and Hall, New York, NY, 1990.

18 P. Frugier, S. Gin, Y. Minet, T. Chave, B. Bonin, N. Godon, J.E. Lartigue, P. Jollivet, A. Ayral, L. De Windt, G. Santarini, SON68 nuclear glass dissolution kinetics: Current state of knowledge and basis of the new GRAAL model, Journal of Nuclear Materials 380 (2008) 8-21

19 T.C. Powers, H.H. Steinour, An Interpretation of some published researches on the alkaliaggregate reaction Part 1-The chemical reactions and mechanism of expansion, J Amer Concr Inst, 51(2) (1955) 497-516.

20 R.D. Aines, H.C. Weed, J.K. Bates, Hydrogen speciation in hydrated layers on nuclear waste glass, Mat Res Sot Symp (1987), 547-558.

21 J.V. Walther, H.C. Helgeson, Calculation of the thermodynamic properties of aqueous silica and the solubility of quartz and its polymorphs at high pressures and temperatures, Am J Sci (1977) 277- 1315-1351.

22 R.K. Iler, The chemistry of silica: Solubility, polymerization, colloid and surface properties, and biochemistry, John Wiley and Sons, Inc., New York, (1979). 
23 S. Sjöberg, Silica in aqueous environments, J Non-Cryst Solids 196 (1996) 51-57.

24 F. Gaboriaud, A. Nonat, D. Chaumont, Aggregation and gel formation in basic silicocalco-alkaline solutions studied: A SAXS, SANS, and ELS study, J Phys Chem B, 103 (28) (1999) 5775-5781.

25 I.L. Svensson, S Sjöberg, L. Ohman, Polysilicate equilibria in concentrated sodium silicate solutions, J Chem Soc Faraday Trans. 1, 82 (1986) 3655-3646.

26 O. Weres, A. Yee, L. Tsao, Kinetics of silica polymerization, J. Colloid Interface Sci 84 (2) (1981) 379-402.

27 L. Nicoleau, A. Nonat, and D. Perrey, The di-and tricalcium silicate dissolutions, Cem. Concr. Res. 47 (2013), 14-30

28 P. Juilland, E. Gallucci, Morpho-topological investigation of the mechanisms and kinetic regimes of alite dissolution, Cement and Concrete Research, 76 (2015): 180-191.

29 S. Liu, K. Ferrand, K. Lemmens, Transport- and surface reaction-controlled SON68 glass dissolution at $30^{\circ} \mathrm{C}$ and $70^{\circ} \mathrm{C}$ and $\mathrm{pH}=13.7$, Applied Geochemistry 61 (2015): 302-311.

30 T.A. Abrajano, J.K. Bates, A.B. Woodland, J.P. Bradley, W.L. Bourcier, Secondary phase formation during nuclear waste glass dissolution, Clays Clay Miner., 38 (5) (1990) 537-548

31 T. Chave, P. Frugier, S. Gin, A. Ayral, Glass-water interphase reactivity with calcium rich solutions, Geochimica et Cosmochimica Acta 75.15 (2011): 4125-4139.

32 S. Mercado-Depierre, F. Angeli, F. Frizon, S. Gin, Antagonist effects of calcium on borosilicate glass alteration." Journal of Nuclear Materials 441.1 (2013): 402-410.

33 M. Fournier, S Gin, P. Frugier, Resumption of nuclear glass alteration: State of the art, J Nuclear Mater, 448 (2014) 348-363

34 R. Snellings, Solution-controlled dissolution of supplementary cementitious material glasses at $\mathrm{pH}$ 13: The effect of solution composition on glass dissolution rates." Journal of the American Ceramic Society 96.8 (2013): 2467-2475.

35 C.A. Utton, R.J. Hand, N.C. Hyatt, S.W. Swanton, S.J. Williams, Formation of alteration products during dissolution of vitrified ILW in a high-pH calcium-rich solution, Journal of Nuclear Materials 442.1 (2013): 33-45.

36 Y. Oka, M. Tomozawa, Effect of alkaline earth ion as an inhibitor to alkaline attack on silica glass. J Non-Cryst Solids 42(1-3) (1980) 535-543

37 Y. Oka, K.S. Ricker, M. Tomozawa, Calcium deposition on glass surface as an inhibitor to alkaline attack. J. Am. Ceram. Soc 62(11-12) (1979) 631-632

38 L. Armelao, A. Bassan, R. Bertoncello, G. Biscontin, S. Daolio, A. Glisent, Silica glass interaction with calcium hydroxide: a surface chemistry approach. J. of Cultural Heritage 1(4) (2000) 375-384

39 N. Rajmohan, P. Frugier, S. Gin, Composition effects on synthetic glass alteration mechanisms: Part 1. Experiments, Chemical Geology 279 (2010) 106-119

40 S. Gin, X. Beaudoux, F. Angéli, C. Jégou, N Godon, Effect of composition on the short-term and long-term dissolution rates of ten borosilicate glasses of increasing complexity from 3 to 30 oxides, Journal of Non-Crystalline Solids, 358, 18-19, (2012) 2559-2570

41 A. Shayan, A. Xu, Value-added utilisation of waste glass in concrete, Cem. Concr. Res., 34 (1) (2004) 81-89

42 C. Shi, Y. Wu, C. Reifler, H. Wang, Characteristics and pozzolanic reactivity of glass powders, Cem. Concr. Res. 35(5) (2005) 987-993 
43 N. Schwarz, N. Neithalath, Influence of a fine glass powder on cement hydration: Comparison to fly ash and modeling the degree of hydration, Cem. Concr. Res. 38 (2008), 429-436

44 L.M. Federico, S.E. Chidiac, Waste glass as a supplementary cementitious material in concrete Critical review of treatment methods, Cem. Concr. Comp 31(8) (2009) 606-610

45 K. Afshinnia, P.R. Rangaraju, Influence of fineness of ground recycled glass on mitigation of alkali-silica reaction in mortars, Construction and Building Materials, 81 (2015) 257-267

46 C. Polley, S.M. Cramer, R.V. De La Cruz, Potential for using waste glass in Portland cement concrete, J. Mater. Civ. Eng., 10(4) (1998) 210-219

47 W. Jin, C. Meyer, S. Baxter, Glascrete - concrete with glass aggregate, ACI Mater. J. 97(2) (2000) 208-213

48 J.R. Wright, C. Cartwright, D. Fura, F. Rajabipour, Fresh and hardened properties of concrete incorporating recycled glass as $100 \%$ sand replacement, ASCE Journal of Materials in Civil Engineering, 26(10), (2014)

49 F. Rajabipour, H. Maraghechi, G. Fischer, Investigating the alkali silica reaction of recycled glass aggregates in concrete materials, J Mater Civ Eng 22 (12) (2010), 1201-1210.

50 F. Rajabipour, H. Maraghechi, S.M.H. Shafaatian, ASR and its mitigation in mortars containing recycled Soda-Lime glass aggregates, 14th International Conference on Concrete Alkali Aggregate Reactions (ICAAR), Austin, Texas (2012).

51 H. Maraghechi, S.M.H. Shafaatian, G. Fischer, F. Rajabipour, The role of residual cracks on alkali silica reactivity of recycled glass aggregates, Cem Concr Compos 34 (2012), 41-47.

52 M.S. Tarnopol, A.E. Junge, Resistance of plate glass to alkaline solutions, J Am Cer Soc, 29(2) (1946) 36-39

53 L.A. Bromley, Thermodynamic properties of strong electrolytes in aqueous solutions, AIChE J, 19(2) (1973) 313-320

54 CRC Handbook of chemistry and physics. 90 ${ }^{\text {th }}$ ed. Boca Raton, Florida: CRC Press, 2010

55 W.H. Casey, G. Sposito, On the temperature dependence of mineral dissolution rates, Geochimica et Cosmochimica Acta , 56 (10) (1992) 3825-3830

56 I.G. Richardson, The calcium silicate hydrates. Cem Concr Res, 2008;38(2):137-58.

57 H.F.W. Taylor, Cement Chemistry, San Diego, California, USA: Academic Press; 1990.

58 R.F. Bleszynski, M.D.A. Thomas, Microstructural studies of alkali-silica reaction in fly ash concrete immersed in alkaline solutions, Advanced Cement Based Materials, 1998, 7(2), 66-78

59 A. Gholizadeh Vayghan, F. Rajabipour, J.L. Rosenberger, Composition-rheology relationships in alkali-silica reaction gels and the impact on the gels' deleterious behavior, Cem Concr Res, 83 (2016) 45-56

60 A. Gholizadeh Vayghan, F. Rajabipour, C. Arndt, The influence of ASR gels composition on their swelling properties, 15th International Conference on Concrete Alkali Aggregate Reactions (ICAAR), Sao Paulo, Brazil (2016)

61 G. Constantinides, F-J. Ulm, The effect of two types of C-S-H on the elasticity of cement-based materials: Results from nanoindentation and micromechanical modeling, Cem Concr Res 34(1) (2004) 67-80

62 E. Bonaccorsi, S. Merlino, A. R. Kampf, The crystal structure of Tobermorite 14A (Plombierite), a C-S-H Phase, J. Am. Ceram. Soc., 88 (3) (2005) 505-512 
63 F. Battocchio, P.J.M. Monteiro, H Wenk, Rietveld refinement of the structures of 1.0 C-S-H and 1.5 C-S-H, Cem Concr Res 42 (11) (2012) 1534-1548

64 M.C.G. Juenger, H.M. Jennings, The use of nitrogen adsorption to assess the microstructure of cement paste, Cem Conc Res 31(6) 883-892

65 K.K. Aligizaki, Pore structure of cement-based materials, Taylor and Francis, London, 2006

66 M.D.A. Thomas, The role of calcium hydroxide in alkali recycling in concrete, Calcium Hydroxide in Concrete, Mater. Sci. Concr., (2001) 225 - 236 (special issue) 
Table 1 Experimental plan that was followed in this research; all glass dissolution experiments were at $60^{\circ} \mathrm{C}$, except for the analysis of the temperature effect

\begin{tabular}{|c|c|c|}
\hline & Glass type & Solution \\
\hline \multicolumn{3}{|c|}{ Phase I: Kinetics experiments } \\
\hline Effect of $\mathrm{pH}$ on glass dissolution rate & SL & $\begin{array}{c}\mathrm{NaOH}(0.01-8.0 \mathrm{M}) \\
\quad \text { (without } \mathrm{Ca})\end{array}$ \\
\hline Effect of temperature on glass dissolution rate & SL & $\begin{array}{l}1.0 \mathrm{M} \mathrm{NaOH} \\
\text { (without } \mathrm{Ca} \text { ) }\end{array}$ \\
\hline Effect of dissolved $\mathrm{Ca}$ on glass dissolution rate & SL and FS & $\begin{array}{c}1.0 \mathrm{M} \mathrm{NaOH} \\
\text { (with and without } \mathrm{Ca} \text { ) }\end{array}$ \\
\hline ICP analysis of the solution & SL and FS & $\begin{array}{c}1.0 \mathrm{M} \mathrm{NaOH} \\
\text { (with and without } \mathrm{Ca} \text { ) }\end{array}$ \\
\hline \multicolumn{3}{|c|}{ Phase II: Characterization of solid products } \\
\hline (E)SEM-EDS & SL & \multirow{4}{*}{$\begin{array}{c}1.0 \mathrm{M} \mathrm{NaOH} \\
\text { (with and without } \mathrm{Ca} \text { ) }\end{array}$} \\
\hline XRD & SL & \\
\hline $\mathrm{N}_{2}$ adsorption & SL & \\
\hline FIB-TEM & SL & \\
\hline
\end{tabular}

Table 2 Oxide composition (wt.\%) of soda-lime and fused silica glass slides

\begin{tabular}{|l|c|c|c|c|c|c|}
\hline & $\mathbf{S i O}_{\mathbf{2}}$ & $\mathbf{C a O}$ & $\mathbf{N a}_{2} \mathbf{O}$ & $\mathbf{A l}_{2} \mathbf{O}_{\mathbf{3}}$ & $\mathbf{M g O}$ & $\mathbf{K}_{\mathbf{2}} \mathbf{O}$ \\
\hline Soda-lime glass (SL) & 73.8 & 7.8 & 12.3 & 0.9 & 3.9 & 0.9 \\
\hline Fused silica glass (FS) & $>99.9$ & - & - & - & - & - \\
\hline
\end{tabular}


Table 3 EDS elemental composition (wt.\%) of soda-lime glass and its corrosion products in "No-CH" reactor after 1 week, and in "SS-CH" reactor after 2 weeks exposure to $1 \mathrm{M} \mathrm{NaOH}$ at $60^{\circ} \mathrm{C}$. Each column is an average composition \pm 1 standard deviation determined from EDS analysis of at least ten areas on a given material.

\begin{tabular}{|c|c|c|c|c|c|}
\hline & \multirow{2}{*}{$\begin{array}{l}\text { Original } \\
\text { soda-lime } \\
\text { glass }\end{array}$} & \multicolumn{3}{|c|}{ Soda-lime No-CH reactor } & $\begin{array}{c}\text { Soda-lime } \\
\text { SS-CH reactor }\end{array}$ \\
\hline & & $\begin{array}{l}\text { Ordered } \\
\text { products }\end{array}$ & $\begin{array}{c}\text { Disordered } \\
\text { products }\end{array}$ & $\begin{array}{l}\text { Average of } \\
\text { all products* }\end{array}$ & $\begin{array}{c}\text { Average of all } \\
\text { products* }\end{array}$ \\
\hline $\mathbf{O}$ & $46.1 \pm 0.6$ & $38.2 \pm 3.3$ & $49.8 \pm 3.6$ & $41.4 \pm 0.6$ & $39.9 \pm 1.0$ \\
\hline Si & $35.6 \pm 1.9$ & $16.3 \pm 4.2$ & $18.7 \pm 2.1$ & $19.8 \pm 1.2$ & $18.5 \pm 2.2$ \\
\hline $\mathrm{Na}$ & $9.4 \pm 1.4$ & $6.1 \pm 3.2$ & $6.4 \pm 4.0$ & $4.3 \pm 1.9$ & $0.89 \pm 0.6$ \\
\hline $\mathbf{C a}$ & $4.9 \pm 0.1$ & $12.6 \pm 3.1$ & $17.7 \pm 2.5$ & $20.9 \pm 3.7$ & $33.4 \pm 3.4$ \\
\hline Mg & $2.8 \pm 0.1$ & $6.1 \pm 3.2$ & $4.4 \pm 3.9$ & $11.6 \pm 1.1$ & $5.8 \pm 2.0$ \\
\hline Al & $0.7 \pm 0.1$ & $2.3 \pm 0.1$ & $2.2 \pm 0.8$ & $1.7 \pm 0.3$ & $1.4 \pm 0.6$ \\
\hline $\mathbf{K}$ & $0.8 \pm 0.1$ & N/D & $\mathrm{N} / \mathrm{D}$ & $\mathrm{N} / \mathrm{D}$ & $\mathrm{N} / \mathrm{D}$ \\
\hline $\mathrm{Ca} / \mathrm{Si}$ (wt) & 0.14 & $0.78 \pm 0.09$ & $1.12 \pm 0.13$ & $1.05 \pm 0.14$ & $1.84 \pm 0.32$ \\
\hline $\mathrm{Ca} / \mathrm{Si}$ (mole) & 0.09 & $0.54 \pm 0.06$ & $0.78 \pm 0.8$ & $0.73 \pm 0.09$ & $1.28 \pm 0.22$ \\
\hline
\end{tabular}

* Average of all products was obtained from EDS analysis on larger areas on collected corrosion products, which contains both ordered and disordered products 


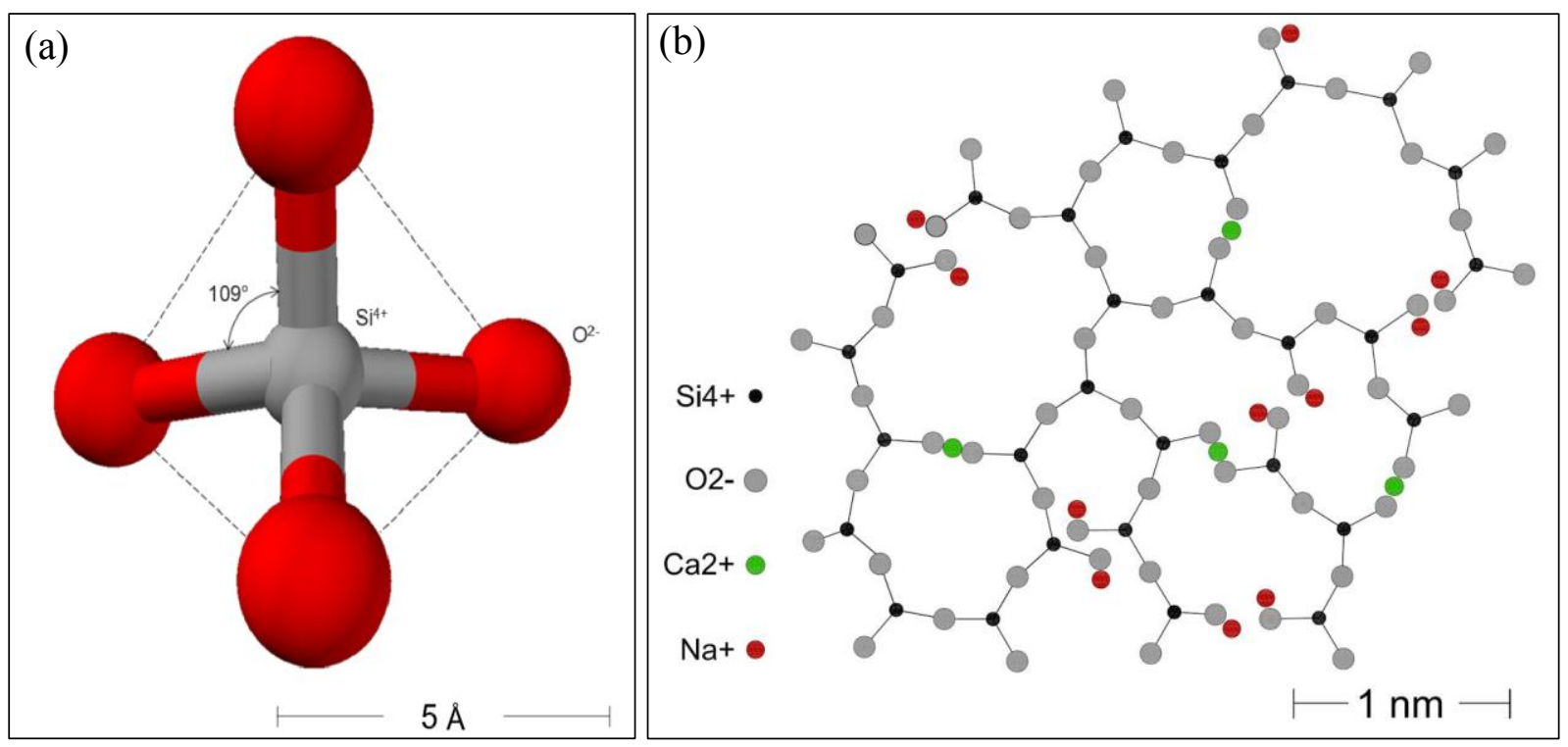

Figure 1 (a) A silica tetrahedron where a silicon atom is surrounded by four oxygen atoms, (b) Two-dimensional representation of the atomic structure of soda-lime silica glass; bridging oxygens (BO) connect two Si atoms while non-bridging oxygens (NBO) are connected to one $\mathrm{Si}$ atom and one $\mathrm{Ca}$ or $\mathrm{Na}$ atom. 


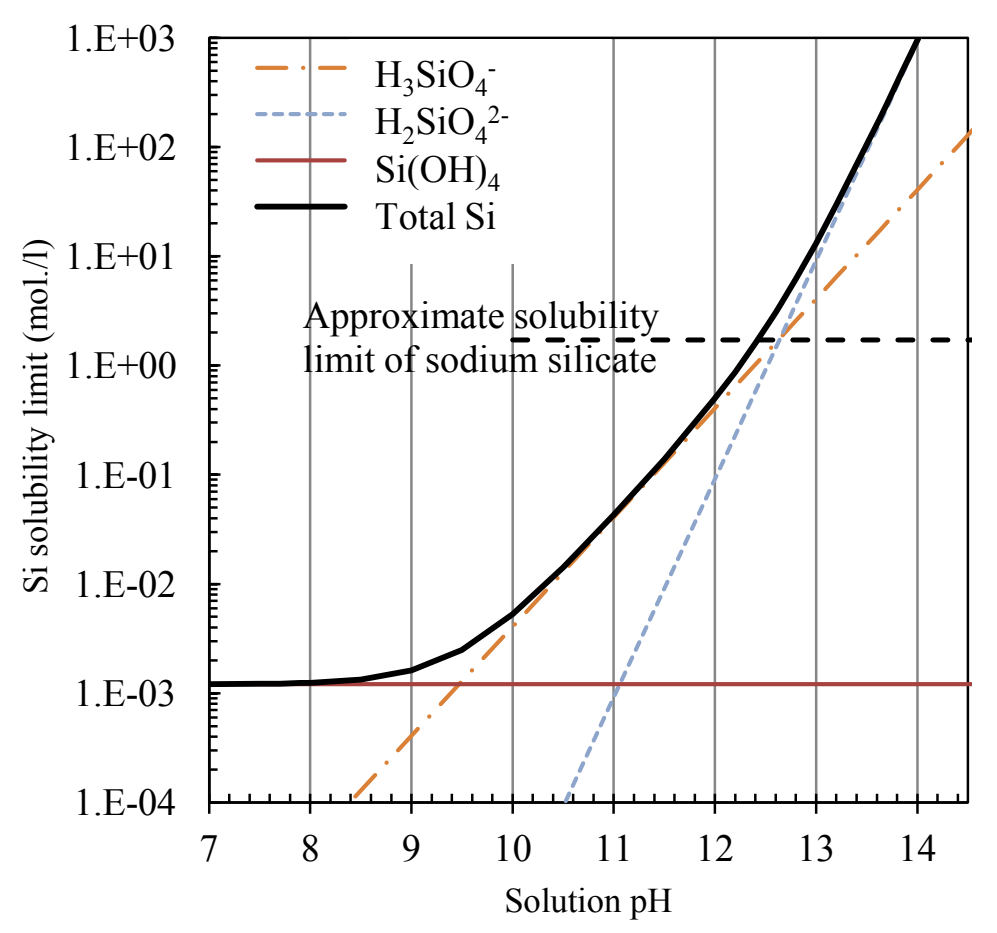

Figure 2 Speciation graph of vitreous silica at $25^{\circ} \mathrm{C}$ using the thermodynamic data presented in Eqs. 3, 4, and 5. Silica solubility increases tremendously with $\mathrm{pH}$. 

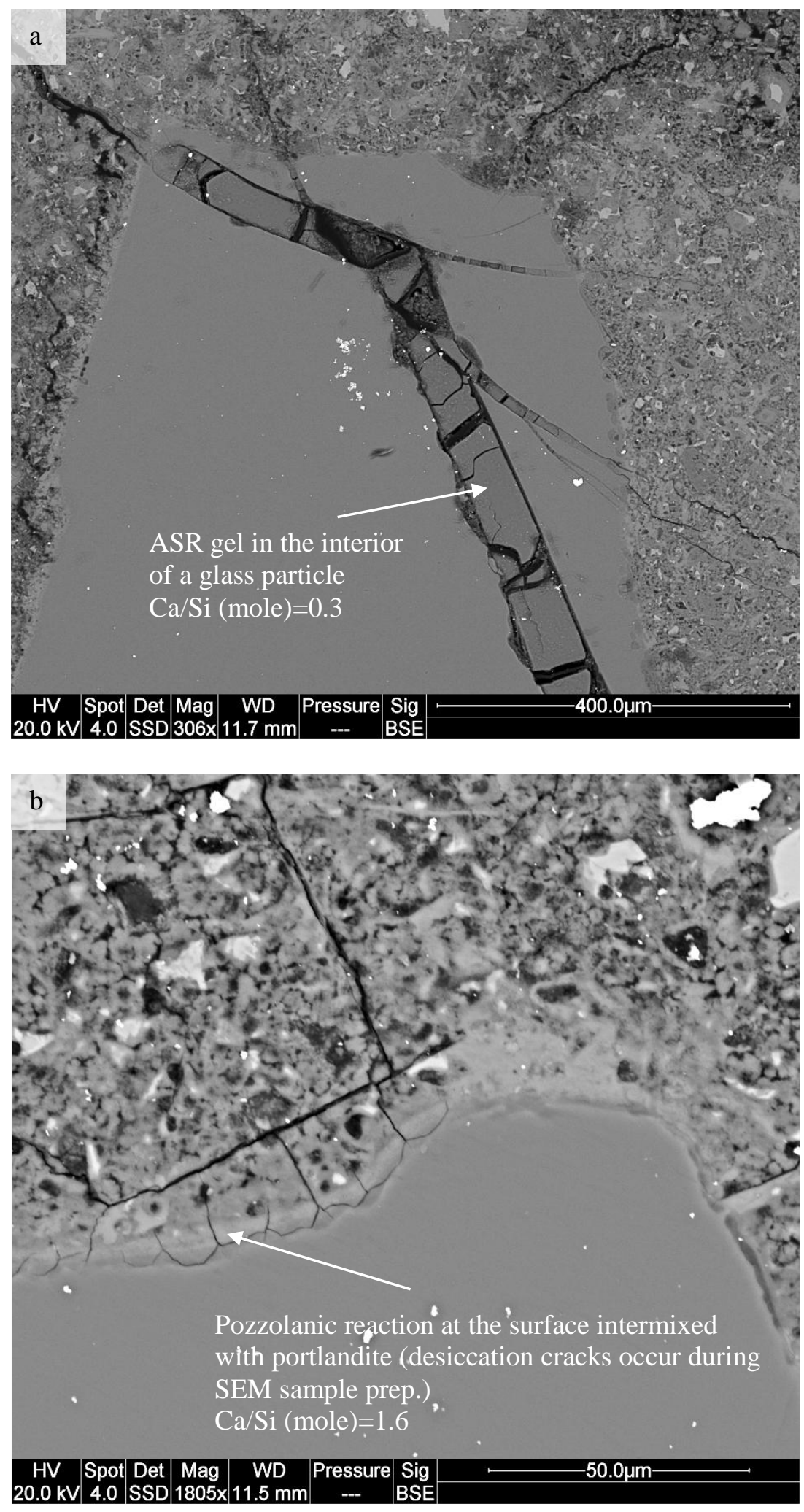

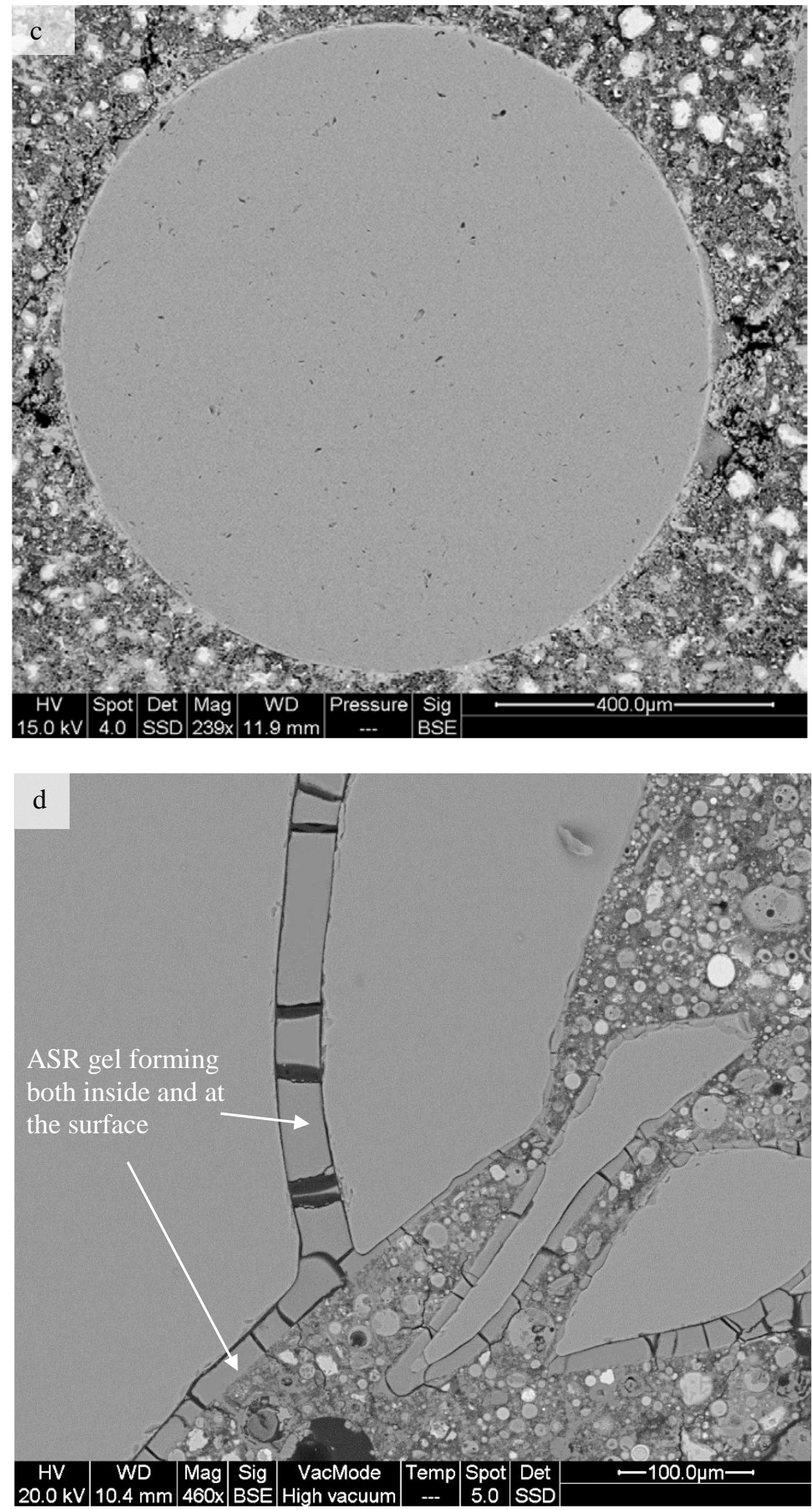

Figure 3 BSE images of mortars containing soda-lime glass: (a) ASR gel formation in the interior of glass particle while the surface remains immune, (b) pozzolanic reaction at the glass-cement paste interface, (c) absence of ASR in crack-free glass beads, (d) ASR in alkali activated fly ash mortar occurring both at the surface and interior of glass 


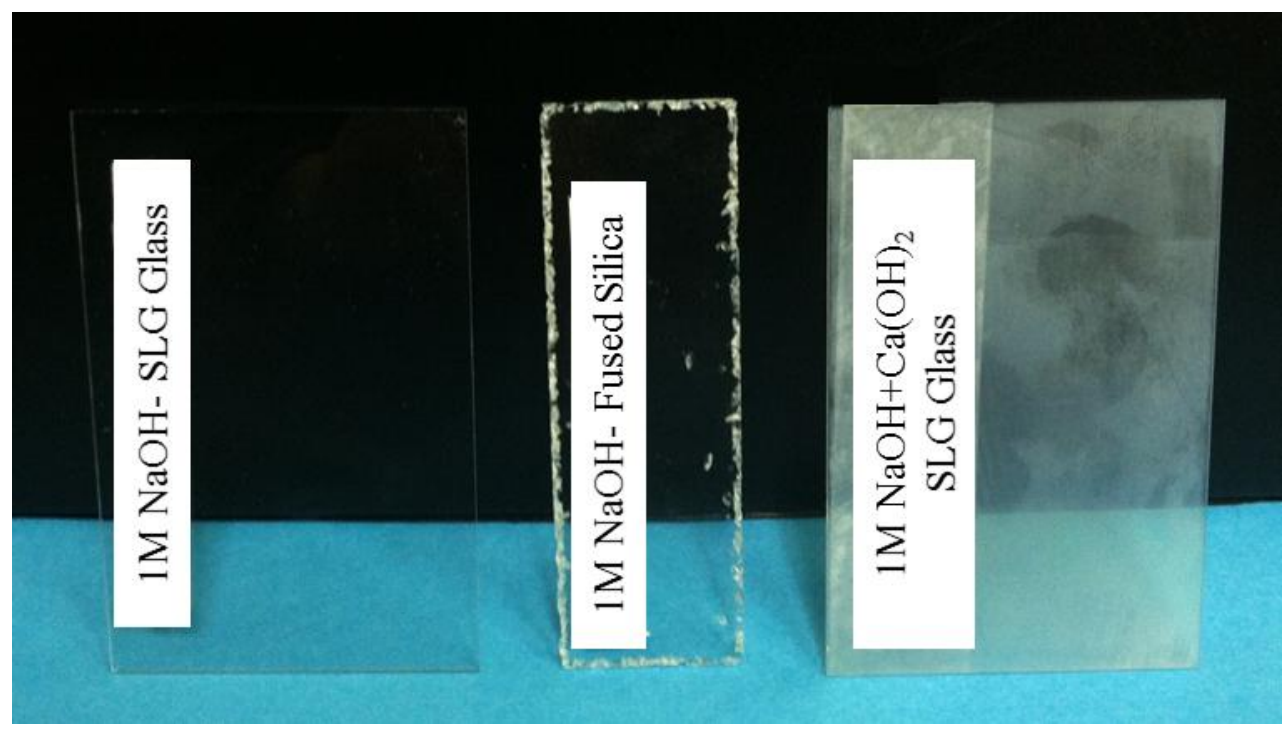

Figure 4 Left: Soda-lime glass exposed for 14 days to $1 \mathrm{M} \mathrm{NaOH}$ in the absence of $\mathrm{Ca}(\mathrm{OH})_{2}$ (soda-lime No-CH system); Middle: Fused silica glass exposed for 28 days to $1 \mathrm{M} \mathrm{NaOH}$; Right: Soda-lime glass exposed for 14 days to $1 \mathrm{M} \mathrm{NaOH}$ saturated with $\mathrm{Ca}(\mathrm{OH})_{2}$ (soda-lime SS-CH system); all slides are washed after exposure 

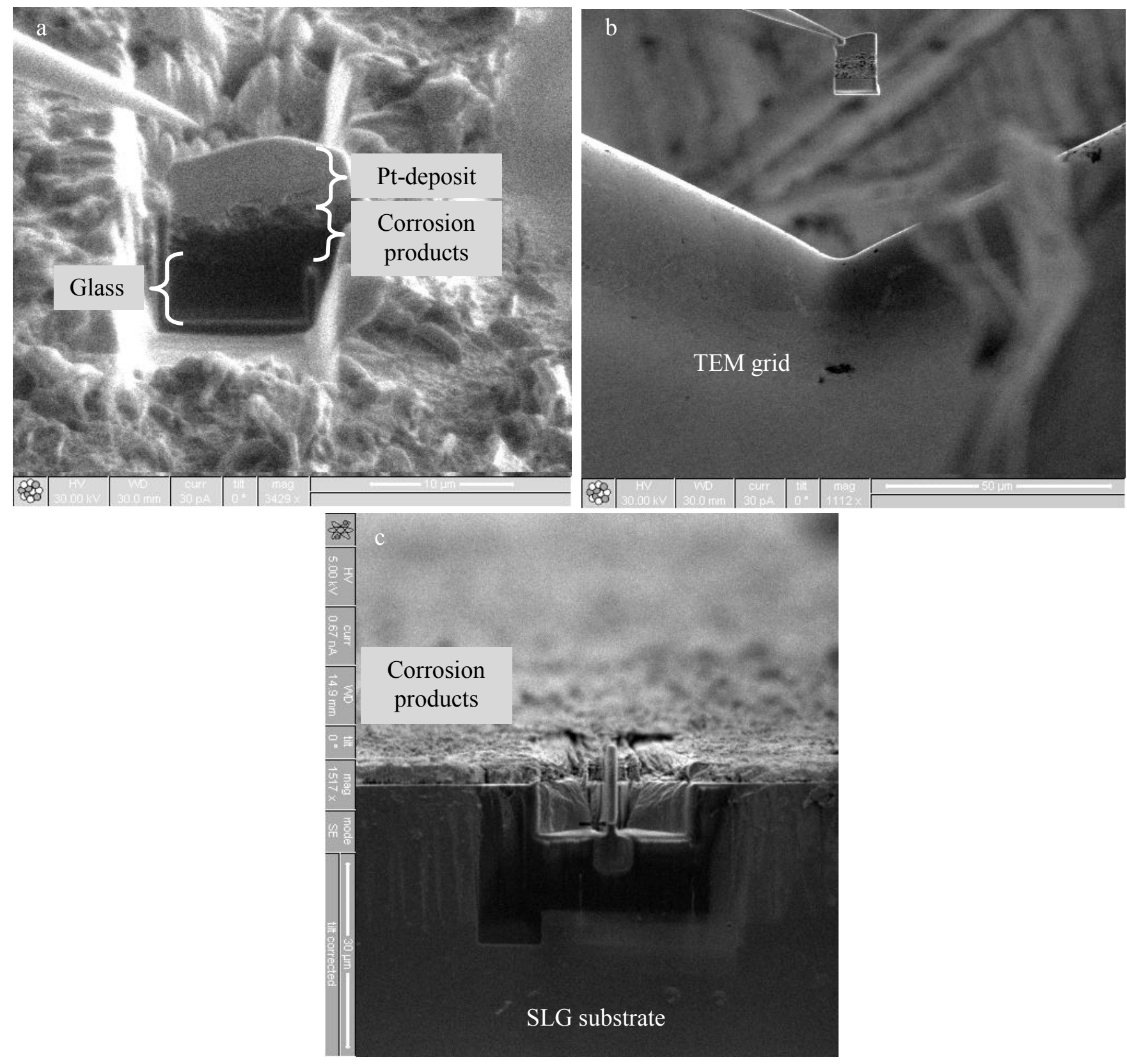

Figure 5 FIB process showing (a) milling from the top and through porous precipitates in soda-lime No-CH system, (b) placement of thin section on TEM grid, and (c) milling through a cross section on soda-lime $\mathrm{SS}-\mathrm{CH}$ system 


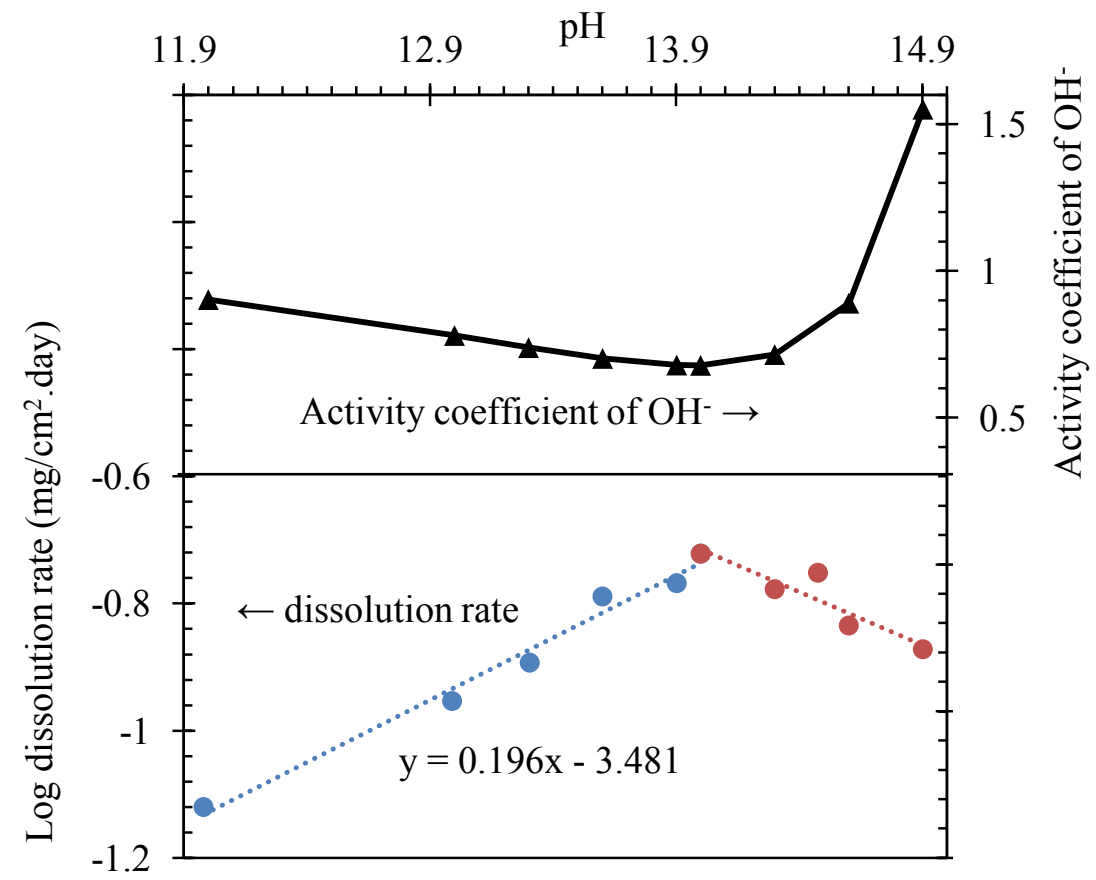

Figure 6 Dissolution rate of soda-lime glass in $\mathrm{NaOH}$ solutions of different $\mathrm{pH}$ values at $60^{\circ} \mathrm{C}$ (lower part of the graph - left axis), and activity coefficient of $\mathrm{OH}^{-}$in the same solutions (upper part of the graph - right axis), calculated based on the Bromley model [48] 

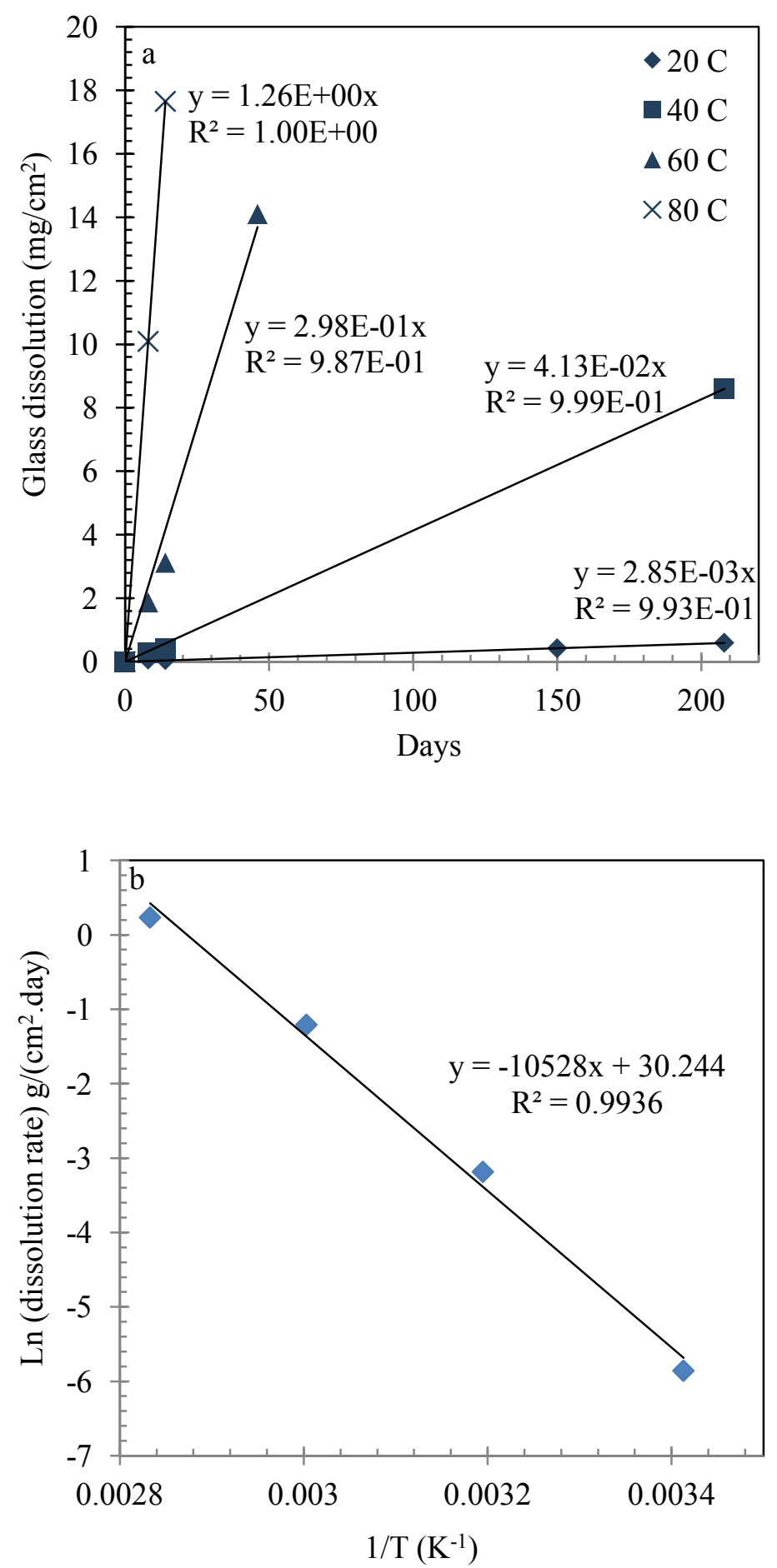

Figure 7 (a) SL slide dissolution mass loss in $1 \mathrm{M} \mathrm{NaOH}$ solution (No-CH) at different temperatures, (b) Linear correlation between $\operatorname{Ln}$ (dissolution rate) versus $1 / \mathrm{T}$ to obtain the activation energy 

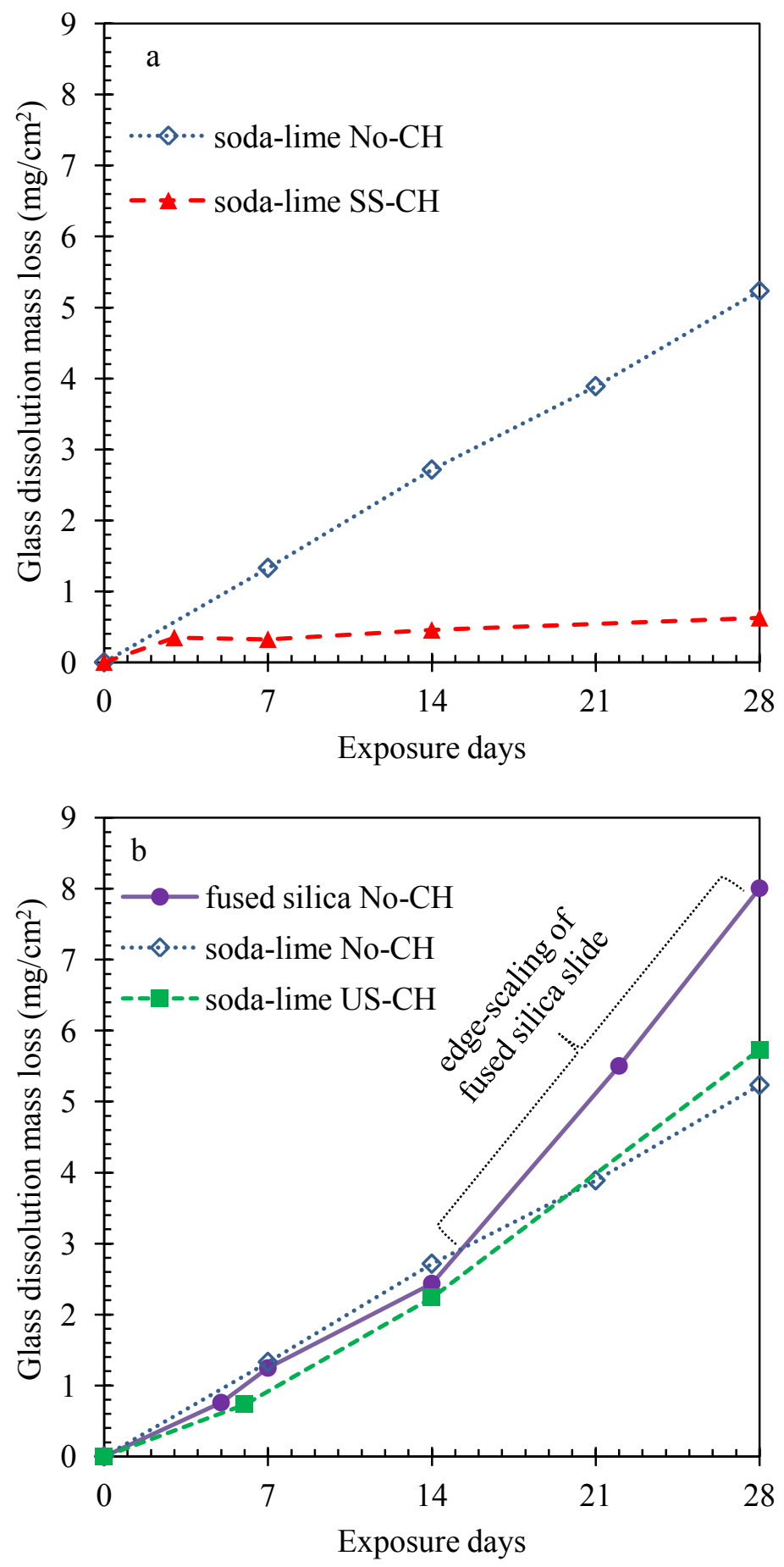

Figure 8 (a) Dissolution mass loss of glass is remarkably reduced in reactors saturated with portlandite (SS-CH) in comparison with No-CH. Precipitate layer was removed prior to mass measurements. (b) Dissolution rate is comparable in reactors undersaturated or without $\mathrm{CH}$. All experiments performed in $1 \mathrm{M} \mathrm{NaOH}$ solution at $60^{\circ} \mathrm{C}$. 

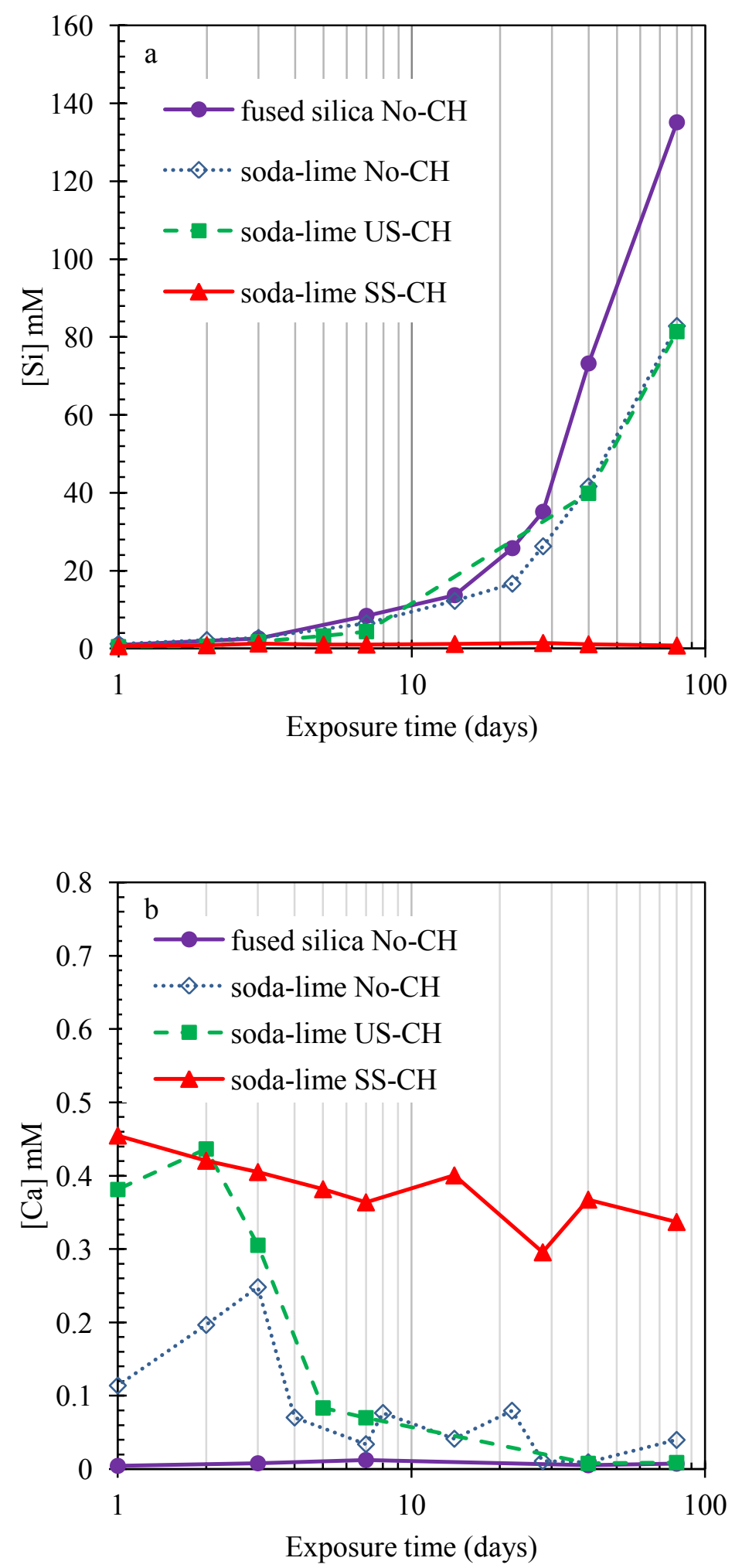

Figure 9 Changes in the concentration of (a) $\mathrm{Si}$, and (b) $\mathrm{Ca}$ in the reactor solutions as a function of time 

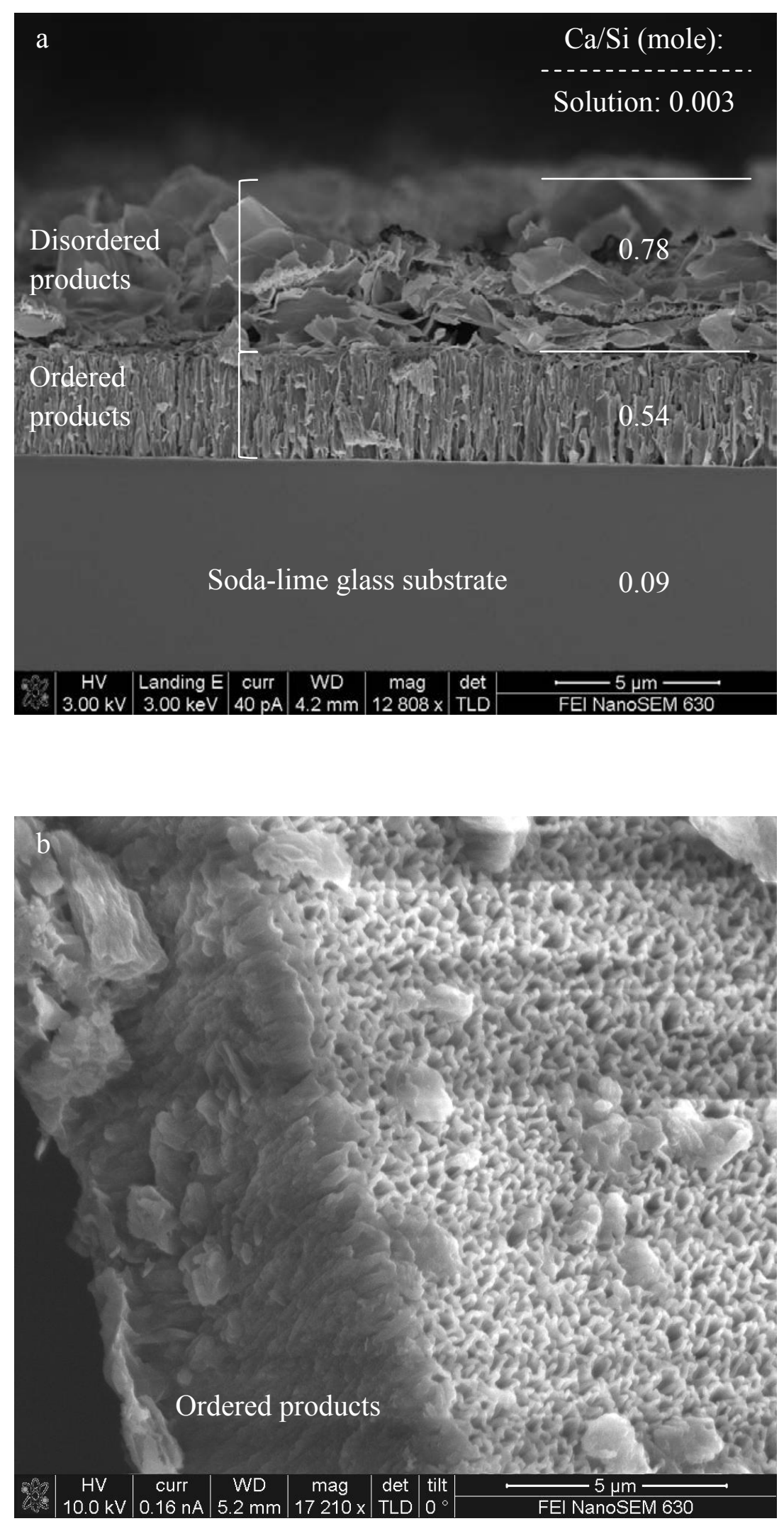


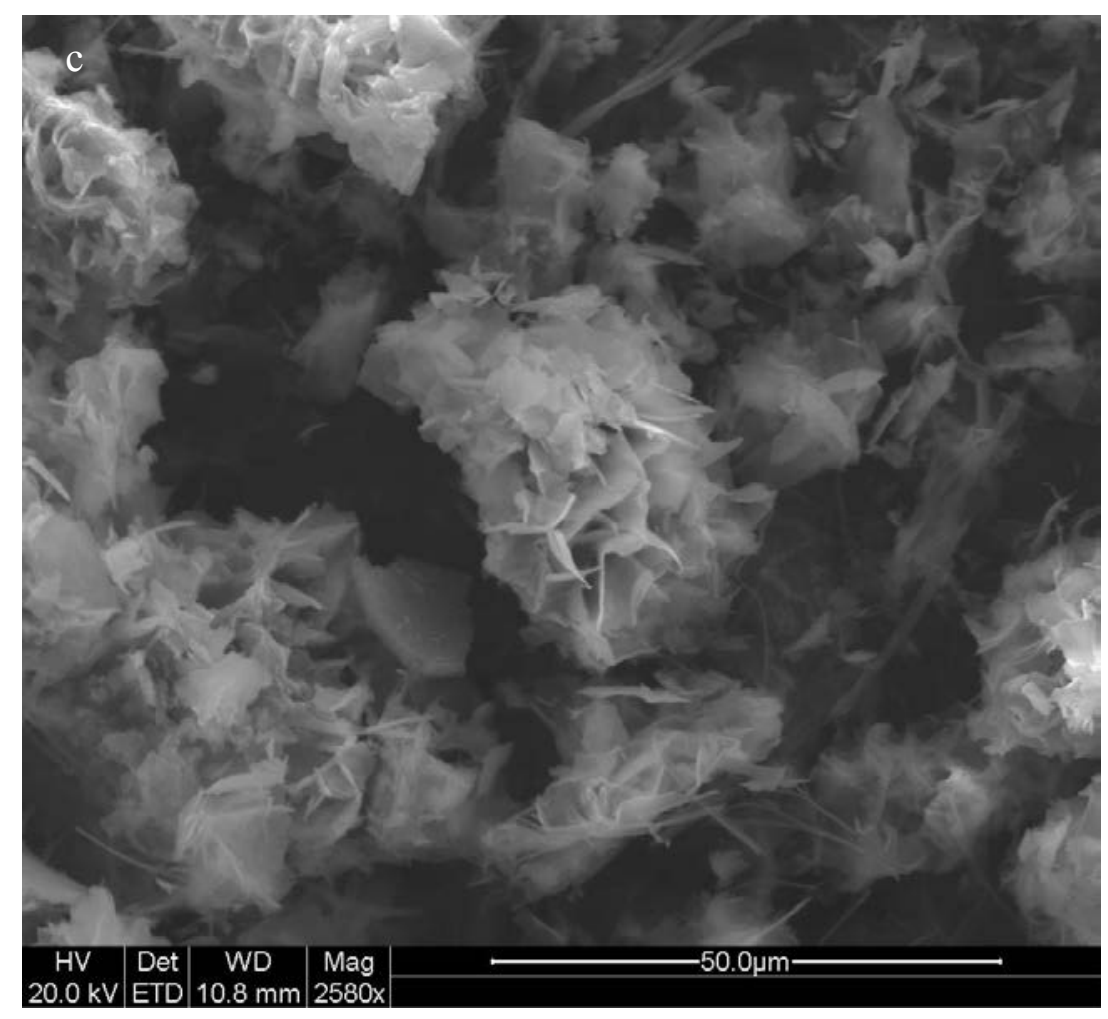

Figure 10 (a) Two types of corrosion products were formed on the surface of soda-lime glass in the No-CH reactor; (b) Ordered (inner) corrosion products after rinsing and removing the (c) Disordered (outer) products. Image "a" was taken after 1 week corrosion, while "b" and "c" correspond to 2 weeks corrosion in $1 \mathrm{M} \mathrm{NaOH}$ at $60^{\circ} \mathrm{C}$. 

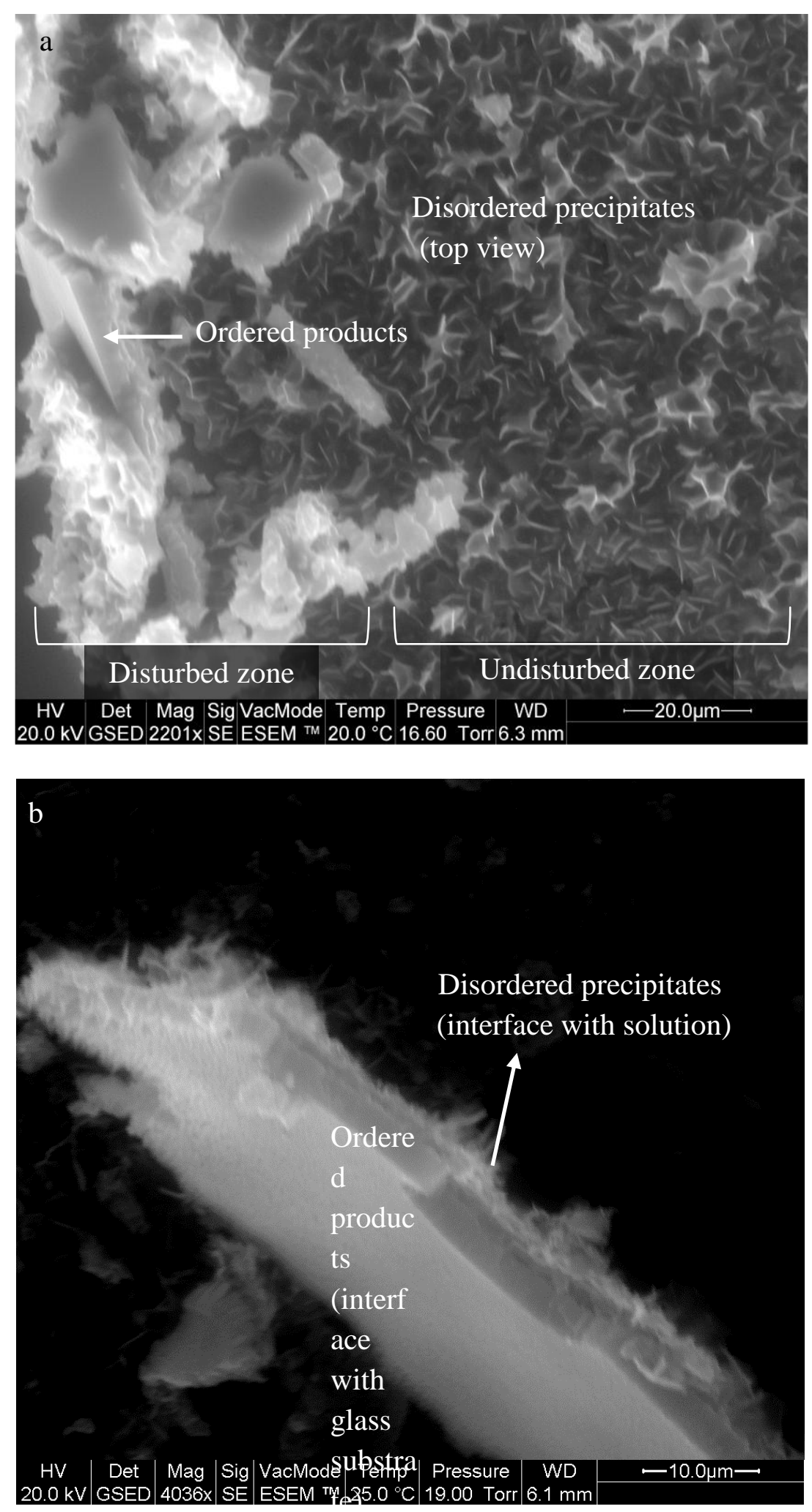

Figure 11 Corrosion products in the "soda-lime No-CH reactor" imaged by ESEM at (a) $\mathrm{T}=20^{\circ} \mathrm{C}, \mathrm{RH}=95 \%$ and, (b) $\mathrm{T}=25^{\circ} \mathrm{C}, \mathrm{RH}=80 \%$.

Images correspond to corrosion in $1 \mathrm{M} \mathrm{NaOH}$ at $60^{\circ} \mathrm{C}$ for 1 week. 


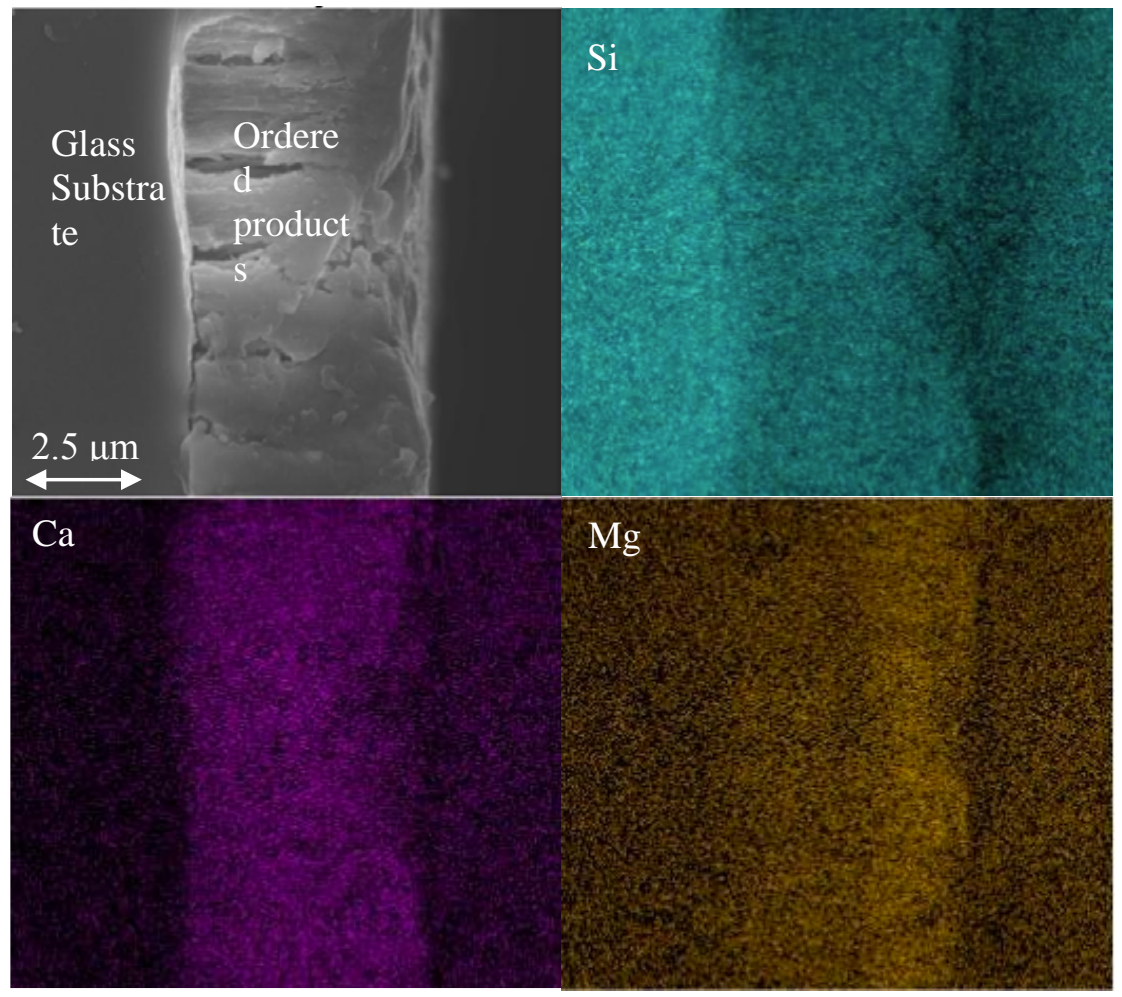

Figure 12 SEM and x-ray EDS maps of soda-lime glass and ordered (inner) corrosion products in the SS-CH reactor after 2 weeks exposure to $1 \mathrm{M} \mathrm{NaOH}$ at $60^{\circ} \mathrm{C}$. Disordered (outer) precipitates were rinsed away prior to imaging. 


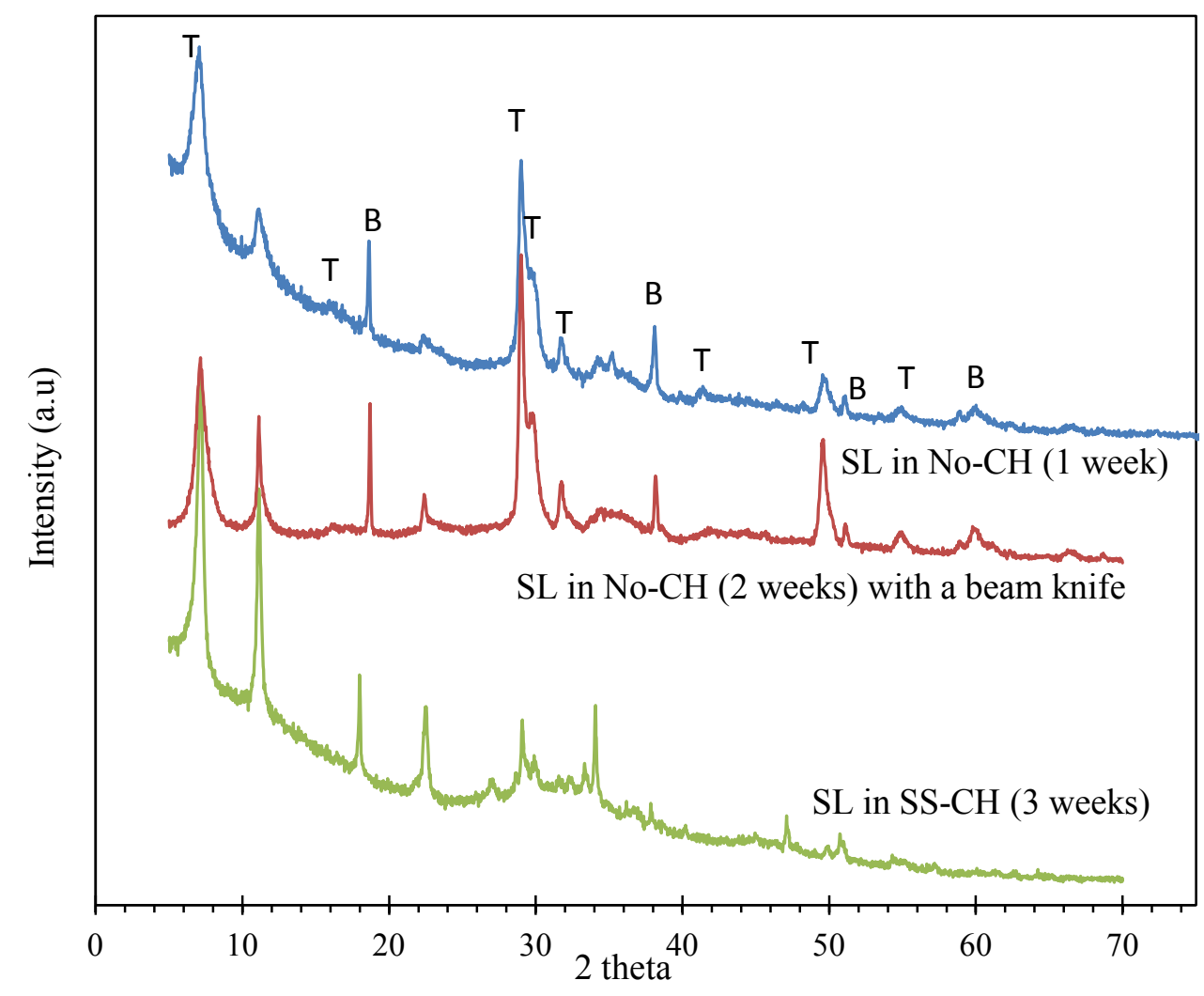

Figure 13 XRD patterns identifying the crystalline corrosion products as tobermorite C-S-H (T) and brucite (B). The SS-CH reactor also shows amorphous C-S-H hump. 


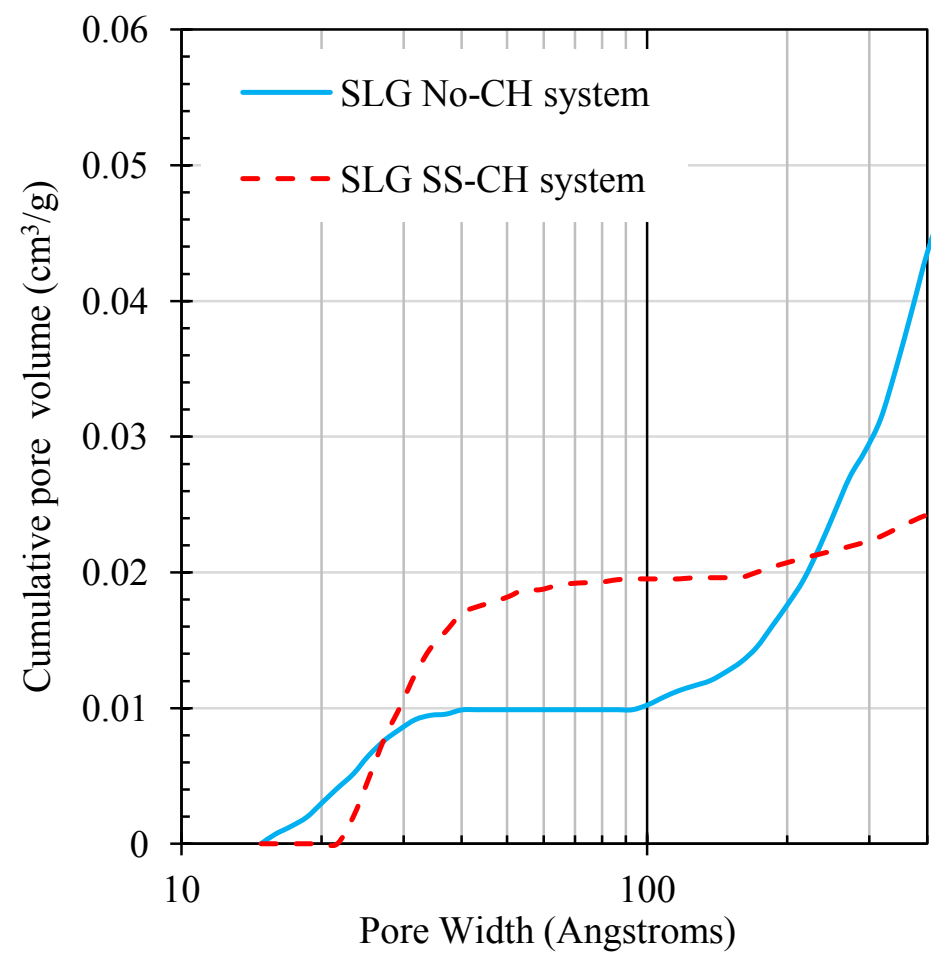

Figure 14 Pore size distribution of corrosion products (1 week, $1 \mathrm{M} \mathrm{NaOH}, 60^{\circ} \mathrm{C}$ ). In reactor saturated with portlandite $(\mathrm{SS}-\mathrm{CH})$, corrosion products have lower porosity and smaller pore size. 


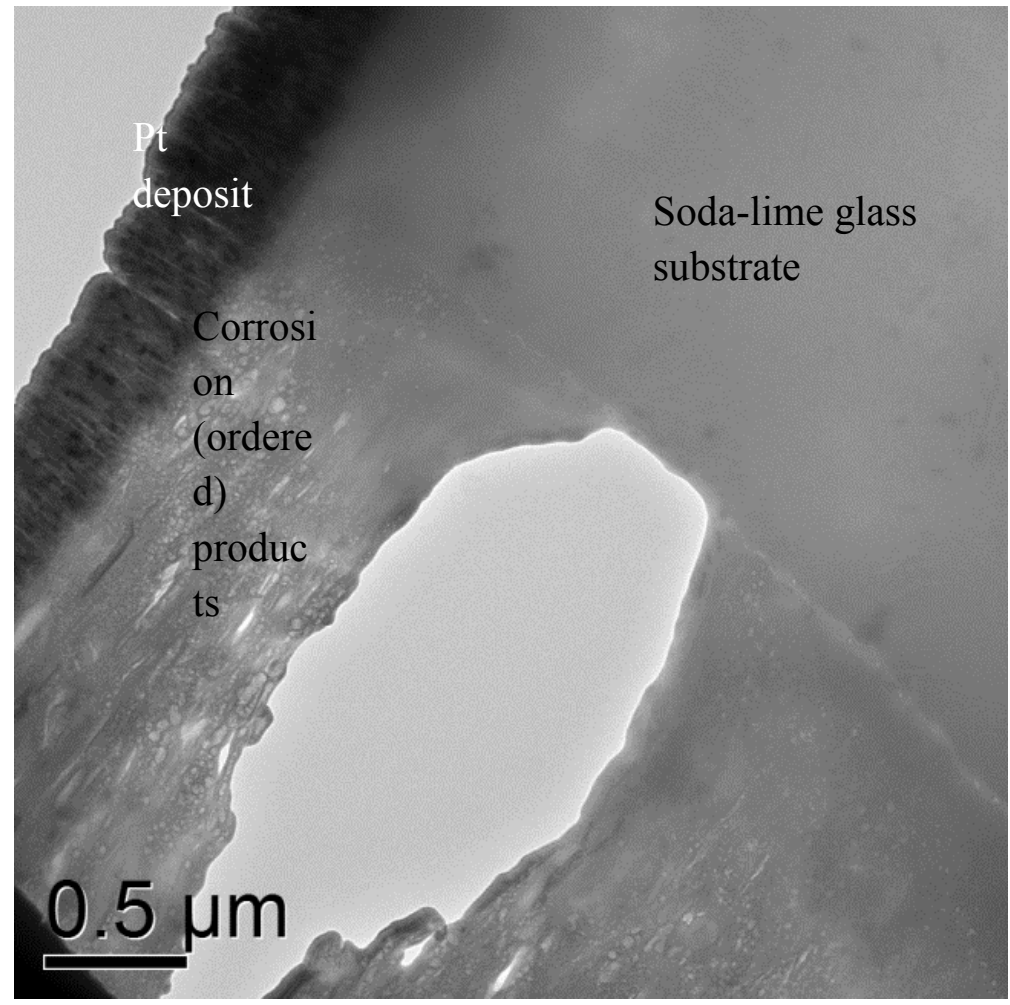

Figure 15 TEM image of the thin section of soda-lime SS-CH glass showing corrosion products on the surface of glass slide

(the hole in the center is a damaged area during the FIB process) 

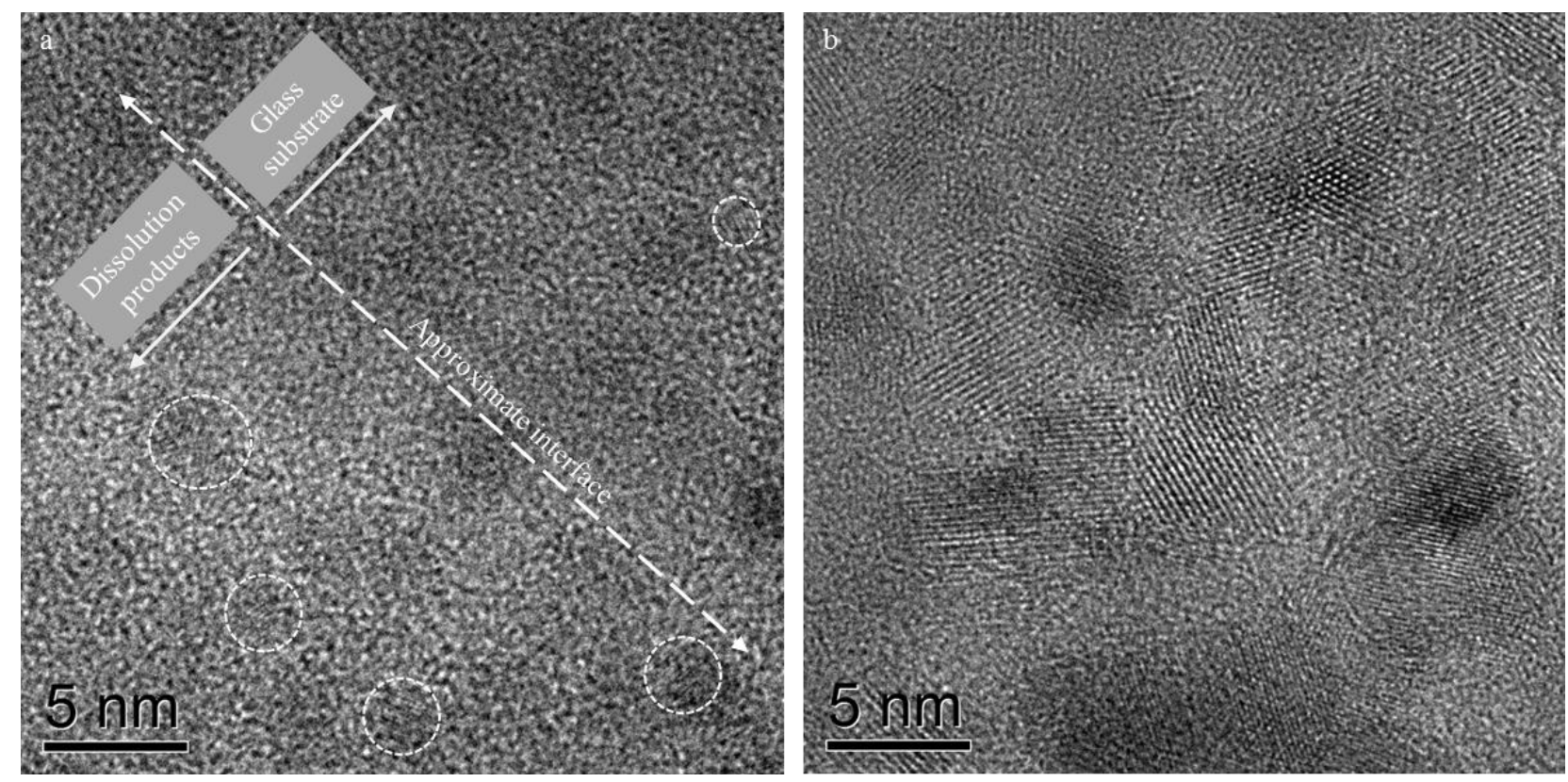

Figure 16 TEM image of (a) the interface of substrate soda-lime glass and corrosion products, showing nucleation of crystals, (b) several crystals further away from the interface 